\title{
Characterization of Cellular and Molecular Heterogeneity of Bone Marrow Stromal Cells
}

\author{
Mona Elsafadi, ${ }^{1,2}$ Muthurangan Manikandan, ${ }^{1}$ Muhammad Atteya, ${ }^{1,3}$ \\ Jamil Amjad Hashmi, ${ }^{4}$ Zafar Iqbal, ${ }^{5}$ Abdullah Aldahmash, ${ }^{1,6}$ Musaad Alfayez, ${ }^{1}$ \\ Moustapha Kassem, ${ }^{1,2}$ and Amer Mahmood ${ }^{1,2}$ \\ ${ }^{1}$ Stem Cell Unit, Department of Anatomy, College of Medicine, King Saud University, Riyadh, Saudi Arabia \\ ${ }^{2}$ Molecular Endocrinology Laboratory (KMEB), Department of Endocrinology, University of Southern Denmark, Odense, Denmark \\ ${ }^{3}$ Department of Histology, Faculty of Medicine, Cairo University, Egypt \\ ${ }^{4}$ Center for Genetics and Inherited Diseases, Taibah University, Al-Madina Al-Munawara, Saudi Arabia \\ ${ }^{5}$ College of Applied Medical Sciences, King Saud Bin Abdulaziz University for Health Sciences (KSAU-HS), \\ National Guards Health Affairs, Riyadh, Saudi Arabia \\ ${ }^{6}$ Prince Naïf Health and Research Center, College of Medicine, King Saud University, Riyadh, Saudi Arabia
}

Correspondence should be addressed to Amer Mahmood; ammahmood@ksu.edu.sa

Received 14 April 2016; Accepted 26 May 2016

Academic Editor: Giorgio Mori

Copyright (c) 2016 Mona Elsafadi et al. This is an open access article distributed under the Creative Commons Attribution License, which permits unrestricted use, distribution, and reproduction in any medium, provided the original work is properly cited.

\begin{abstract}
Human bone marrow-derived stromal stem cells (hBMSC) exhibit multiple functions, including differentiation into skeletal cells (progenitor function), hematopoiesis support, and immune regulation (nonprogenitor function). We have previously demonstrated the presence of morphological and functional heterogeneity of hBMSC cultures. In the present study, we characterized in detail two hTERT-BMSC clonal cell populations termed here CL1 and CL2 that represent an opposing phenotype with respect to morphology, markers expression: alkaline phosphatase (ALP) and CD146, and ex vivo differentiation potential. CL1 differentiated readily to osteoblasts, adipocytes, and chondrocytes as shown by expression of lineage specific genes and proteins. Whole genome transcriptome profiling of CL1 versus CL2 revealed enrichment in CL1 of bone-, mineralization-, and skeletal muscle-related genes, for example, ALP, POSTN, IGFBP5 BMP4, and CXCL12. On the other hand, CL2 transcriptome was enriched in immune modulatory genes, for example, CD14, CD99, NOTCH3, CXCL6, CFB, and CFI. Furthermore, gene expression microarray analysis of osteoblast differentiated CL1 versus CL2 showed significant upregulation in CL1 of bone development and osteoblast differentiation genes which included several homeobox genes: TBX15, HOXA2 and HOXA10, and IGF1, FGFR3, BMP6, MCAM, ITGA10, IGFBP5, and $A L P$. siRNA-based downregulation of the ALP gene in CL1 impaired osteoblastic and adipocytic differentiation. Our studies demonstrate the existence of molecular and functional heterogeneity in cultured hBMSC. ALP can be employed to identify osteoblastic and adipocytic progenitor cells in the heterogeneous hBMSC cultures.
\end{abstract}

\section{Introduction}

Human bone marrow stromal (also known as skeletal or mesenchymal) stem cells (hBMSC) are increasingly employed in clinical trials for enhancing tissue regeneration following injury [1]. Typically, hBMSC are isolated by their ability to adhere to the plastic surfaces of in vitro culture plates. However, the cultured hBMSC exhibit morphological heterogeneity suggesting the presence of functional heterogeneity $[2,3]$. It has also been suggested that the use of heterogeneous cell populations in clinical trials of hBMSC-based therapies caused variability in the observed treatment effects [4]. Thus, for the efficient use of hBMSC in therapy, better cellular and molecular characterization of hBMSC is required $[1,4]$.

There exist no specific markers that define the hBMSC phenotype. The plastic-adherent hBMSC are defined by the presence of surface expression of some CD surface markers with variable sensitivity and specificity [1]. Single cell clonal analysis revealed that only $25 \%$ of the cells are true stem cells based on their ability to differentiate into osteoblasts, 
adipocytes, and chondrocytes (trilineage differentiation) and to form heterotopic bone and bone marrow organ when implanted in vivo subcutaneously in immune deficient mice [5]. The identity of the remaining cells is not clarified, but they may represent lineage-committed cells [3]. Therefore, it is plausible that functional heterogeneity exists in cultured hBMSC, reflecting the in vivo functional and developmental heterogeneity of hBMSC [6].

In addition to their ability to differentiate into skeletal tissue cells (known as progenitor function), hBMSC possess immunomodulatory characteristics (known as nonprogenitor functions) [7]. It is not clear whether these different functions are mediated by a number of independent subpopulations within the hBMSC [2]. Only a few studies have tried to identify the subpopulation within cultured hBMSC based on surface markers, for example, STRO1 and alkaline phosphatase (ALP), but limited molecular phenotyping has been conducted [8].

We have previously demonstrated the presence of morphological and functional heterogeneity of clones isolated from telomerized hMSC (hMSC-TERT) cell line [3]. The aim of the present study was therefore to further study in detail the heterogeneity of cultured hBMSC as demonstrated by two clonal cell lines with opposite cellular and functional phenotype. We also employed the DNA microarrays to define their molecular signature and signaling pathways associated with their functional phenotype.

\section{Experimental Procedures}

2.1. Cell Culture. As a model for hBMSC, we employed immortalized hBMSC-TERT cell line that is created from normal human BMSC by overexpression of human telomerase reverse transcriptase gene (hTERT) [9]. The hBMSCTERT cells have been extensively characterized, and they exhibit similar cellular and molecular phenotype to primary MSC [10]. CL1 and CL2 cells are clonal cell populations of hBMSC-TERT identified in long term culture (passage numbers 15-25) of hBMSC-TERT and were chosen based on their distinct and different morphologies. Cells were cultured in Dulbecco's Modified Eagle Medium (DMEM) supplemented with D-glucose $4500 \mathrm{mg} / \mathrm{L}, 4 \mathrm{mM}$ L-glutamine and $110 \mathrm{mg} / \mathrm{L}$ sodium pyruvate, $10 \%$ Fetal Bovine Serum (FBS), 1x penicillin-streptomycin (Pen-strep), and nonessential amino acids (all purchased from Gibco-Invitrogen, USA). For some control experiments, primary bone marrow derived MSC (phBMSC) were employed. Sixty milliliters of bone marrow was aspirated from the iliac crest bone of consenting healthy donors. This procedure was approved by the King Khalid University Hospital-King Saud University ethics committee. phBMSC were isolated from bone marrow mononuclear cells by plastic adherence as described previously [9].

2.2. Cell Proliferation. Cell proliferation rate was determined by counting cell number and calculating population doubling (PD) rate. The cells were cultured in $25 \mathrm{~cm}^{2}$ tissue culture Petri dish at cell density $0.5 \times 10^{6}$ cells $\left(28000\right.$ cells $\left./ \mathrm{cm}^{2}\right)$. At confluence, the cells were trypsinized and counted manually by hemocytometer. At each passage, population doubling was determined by the following formula: $\log N / \log 2$, where $N$ is the number of cells at confluence divided by the initial cell number. Cumulative PD level is the sum of population doublings, and $\mathrm{PD}$ rate is $\mathrm{PD} /$ time in culture.

2.3. Flow Cytometry. Cells were trypsinized to a single cell suspension, were recovered by centrifugation at $200 \mathrm{~g}$ for $5 \mathrm{~min}$, washed twice in ice-cold PBS supplemented with $2 \% \mathrm{BSA}$, and resuspended at a concentration of $10^{5}$ cells/antibody. After incubation with the preconjugated antibodies, or matched isotype controls, for $30 \mathrm{~min}$ on ice in the dark, cells were washed with PBS, resuspended in $500 \mu \mathrm{L}$ of PBS, and analyzed in the BD FACSCalibur flow cytometer (BD Biosciences). Living cells were gated in a dot plot of forward versus side scatter signals acquired on a linear scale. At least 10,000 gated events were acquired on a log fluorescence scale. Positive staining was distinct as the emission of a fluorescence signal that surpassed levels achieved by $>99 \%$ of control cell population stained with corresponding isotype antibodies. The ratios of fluorescence signals versus scatter signals were calculated, and histograms were generated using the software Cell Quest Pro Software Version 3.3 (BD Biosciences). The following antibodies were used all from BD Biosciences: FITC-PE-APC-Mouse IgGlk isotype control, APC-Mouse Anti-Human CD44 (\#559942), FITC-Mouse Anti-Human CD63 (\#557305), PE-Mouse AntiHuman CD73 (\#550257), PE-Mouse Anti-Human CD105 (\#560839), PE-Mouse Anti-Human CD146 (\#550315), PEMouse Anti-Human CD166 (\#560903), and Alexa Fluor ${ }^{\circledR} 488$ Mouse Anti-Human Alkaline Phosphatase (\#561495).

2.4. Electron Microscopy. After trypsinizing the hBMSC cells from the flasks or 6-well plates were collected, the samples were washed with PBS, and the pellets were resuspended directly in $2.5 \%$ glutaraldehyde in $0.1 \mathrm{M}$ phosphate buffer $(\mathrm{pH}$ 7.2), and kept at $4^{\circ} \mathrm{C}$ for $4 \mathrm{hr}$. First, the cells were washed with $0.1 \mathrm{M}$ phosphate buffer ( $\mathrm{pH}$ 7.2) and transferred to $1 \%$ osmium tetroxide (OsO4) solution in $0.1 \mathrm{M}$ phosphate buffer ( $\mathrm{pH} 7.2$ ) for two hr. The cells were dehydrated in ascending grades of ethanol. The cells were then resuspended in acetone and were aliquoted into BEEM embedding capsules and infiltrated with acetone: resin mixture followed by embedding in a pure resin mixture for two hr. Semithin sections $(0.5 \mu \mathrm{m}$ thickness) and ultrathin sections (70 nm thickness) were prepared, examined, and photographed under a transmission electron microscope (TEM) (Jeol 1010, Jeol, Tokyo, Japan).

2.5. In Vitro Osteoblast Differentiation. Cells were grown in standard DMEM growth medium in 6-well plates at $20,000 \mathrm{cell} / \mathrm{cm}^{2}$. When $70-80 \%$ confluence was achieved, test cells were cultured in DMEM supplemented with osteoblastic induction mixture (referred to as OS) containing 10\% FBS, $1 \%$ Pen-strep, $50 \mu \mathrm{g} / \mathrm{mL}$ L-ascorbic acid (Wako Chemicals, Neuss, Germany), $10 \mathrm{mM} \beta$-glycerophosphate (Sigma) and $10 \mathrm{nM}$ calcitriol ( $1 \alpha, 25$-dihydroxyvitamin D3; Sigma), and $10 \mathrm{nM}$ dexamethasone (Sigma); noninduced cells (referred to as Cont) were cultured in normal growth media for the same duration as induced. The media were replaced three times per week. Cells cultured in standard culture medium were considered as control. At day 14 of differentiation, 
mineralized nodules became apparent and were stained with Alizarin Red S and ALP.

2.6. In Vitro Adipocyte Differentiation. Cells were grown in standard DMEM growth medium in 6-well plates at 0.3 $\times 10^{6}$ cells $/ \mathrm{mL}$. At $90-100 \%$ confluence, cells were cultured in DMEM supplemented with adipogenic (Adip) induction mixture containing 10\% FBS, 10\% Horse Serum (Sigma), $1 \%$ Pen-strep, $100 \mathrm{nM}$ dexamethasone, $0.45 \mathrm{mM}$ isobutyl methylxanthine (Sigma), $3 \mu \mathrm{g} / \mathrm{mL}$ insulin (Sigma), and $1 \mu \mathrm{M}$ Rosiglitazone (Novo Nordisk, Bagsvaerd, Denmark). The media were replaced three times per week. Cells cultured in standard culture medium were considered as control. From day 3 of differentiation, small lipid droplets became visible and at day 7 they were stained with Oil Red-O and Nile red.

\subsection{In Vitro Chondrogenic Differentiation. Both CL1 and CL2} cells were trypsinized and counted, around $1 \times 10^{6}$ cells taken in each $15 \mathrm{~mL}$ conical tube centrifuged at $400 \times \mathrm{g}$ for 5 minutes. For chondrocyte differentiation pellet culture system used, chondrocyte induction was done in media containing advanced DMEM/F12 supplemented with 1\% ITS Premix Tissue Culture Supplement, 100 nM dexamethasone, Glutamax, and $10 \mathrm{ng} / \mathrm{mL}$ transforming growth factor-beta-3 (TGF $\beta-3)$. Cells were maintained in chondrocyte differentiation media for 21 days and changed every two days.

\subsection{Cytochemical Staining}

2.8.1. Alkaline Phosphatase (ALP) Staining. CL1 and CL2 cells were stained before OS differentiation for the basal ALP expression and after OB differentiation at day 7 of induction. Cells cultured in 6-well plates were washed in PBS -/(-Ca, -Mg) and fixed in acetone/citrate buffer $10 \mathrm{mM}$ at $\mathrm{pH} 4.2$ for $5 \mathrm{~min}$ at room temperature. The Naphthol/Fast Red stain [0.2 mg/mL Naphthol AS-TR phosphate substrate (Sigma)] [0.417 mg/mL of Fast Red (Sigma)] was added for one hour at room temperature.

Histological tissue blocks were sectioned at 4 microns. Immunohistochemical staining was performed on CL1 and CL2 chondrocyte 3D pellets using DAKO EnVision and PowerVision according to the manufacturer's instructions (DAKO, Glostrup, Denmark). Briefly, paraffin sections were incubated for 1 hour at room temperature with primary antibodies diluted in ChemMate (DAKO) (Human Anti-Col10 and Human Anti-Col-2 ABI). Sections were washed subsequently in Tris-buffered saline (TBS, $0.05 \mathrm{M}, \mathrm{pH}$ 7.4), incubated for 30 minutes with secondary anti-mouse Ig/HRPconjugated polymers (K4001, En Visionp, DAKO), and visualized with 3,30-diaminobenzidine tetrahydrochloride (DAB, S3000, DAKO) or with 3-amino-9-ethylcarbazole (AEC, DAKO) according to manufacturer's instruction. Controls were performed with nonimmune immunoglobulins of the same isotype as the primary antibodies (negative controls) and processed under identical conditions. Alcian blue staining was used to detect chondrocytes. Sections of paraffinembedded implants were stained with Alcian blue (Sigma) solution, $\mathrm{pH} 2.5$; at this $\mathrm{pH}$ all the glycoproteins (neutral and acidic) will be stained blue.
2.9. Alizarin Red S Staining for Mineralized Matrix. Sevenday-old OS differentiated cells in 6-well plates were used for Alizarin Red S staining. The cell layer was washed with PBS and then fixed with $70 \%$ ice-cold ethanol for $1 \mathrm{hr}$ at $-20^{\circ} \mathrm{C}$. After removing the ethanol, the cell layer was rinsed with distilled water and stained with $40 \mathrm{nM}$ AR-S (Sigma) pH 4.2 for 10 minutes at room temperature. Excess dye was washed off with water followed by a wash with PBS for few minutes to minimize nonspecific AR-S stain.

For quantifying the Alizarin Red S staining, the air-dried plates, the Alizarin Red S dye was eluted in $800 \mu \mathrm{L}$ of acetic acid incubated in each well for 30 minutes at room temperature as described [11] and measured in spectrophotometer (BioTek, Epoch) at $405 \mathrm{~nm}$.

2.10. Quantitative ALP Activity. To quantify ALP activity in CL1 and CL2 hBMSC before and after OS differentiation, we used the BioVision ALP activity colorimetric assay kit (BioVision, Inc, CA, USA) with some modifications. Cells were cultured in 96-well plates under normal conditions; then on day of analysis, wells were rinsed once with PBS and were fixed using 3.7\% formaldehyde in $90 \%$ ethanol for 30 seconds at room temperature. Subsequently, fixative was removed, and $50 \mu \mathrm{L}$ of pNPP solution was added to each well and incubated for 1 hour in the dark at room temperature. The reaction was subsequently stopped by adding $20 \mu \mathrm{L}$ stop solution and gently shaking the plate. OD was then measured at $405 \mathrm{~nm}$.

2.11. Oil Red-O Staining for Lipid Droplets. CL1 and CL2 cells differentiated to adipocytes with Adip induction media at day 7 were used. Accumulated cytoplasmic lipid droplets were visualized by staining with Oil Red-O. After washing cells grown in 6-well plates with PBS, the cells were fixed in $4 \%$ formaldehyde for $10 \mathrm{~min}$ at room temperature and then rinsed once with 3\% isopropanol and stained for $1 \mathrm{hr}$ at room temperature with filtered Oil Red-O staining solution (prepared by dissolving $0.5 \mathrm{~g}$ Oil Red-O powder in $60 \%$ isopropanol). To quantify staining of fat droplets, Oil Red$\mathrm{O}$ was used as a stain. Oil Red-O was eluted by adding $100 \%$ isopropanol to each well, and color changes were measured by spectrophotometer at $510 \mathrm{~nm}$ (BioTek Spectrophotometer, Epoch).

\subsection{Nile Red Fluorescence Determination and Quantification} of Adipogenesis. A stock solution of Nile red $(1 \mathrm{mg} / \mathrm{mL})$ in DMSO was prepared and stored at $-20^{\circ} \mathrm{C}$ protected from light. Staining was performed on unfixed cells. Cultured undifferentiated and day 7 adipocyte differentiated cells were grown in Corning polystyrene; flat bottom 96-well TCtreated black microplates (Corning, NY, USA) were washed once with PBS. The dye was then added directly to the cells $(5 \mu \mathrm{g} / \mathrm{mL}$ in PBS), and the preparation was incubated for $10 \mathrm{~min}$ at room temperature and then washed twice with PBS. Fluorescent signal was measured using SpectraMax/M5 fluorescence spectrophotometer plate reader (Molecular Devices Co, Sunnyvale, CA, USA) using bottom well-scan mode where nine readings were taken per well using Ex $(485 \mathrm{~nm})$ and Em $(572 \mathrm{~nm})$ spectra. 
2.13. Quantitative Real-Time PCR ( $q R T-P C R)$ Analysis. Total RNA was extracted using MagNA pure compact RNA isolation kit (Roche Applied Science, Germany, Cat number 04802993001) in an automated MagNA pure compact system (Roche, Germany) as recommended by the manufacturer. The total RNA was quantified by Nanodrop spectrophotometer (Nanodrop 2000, Thermo Scientific, USA). Complementary DNA (cDNA) was synthesized from $1 \mu \mathrm{g}$ of the RNA samples using High Capacity cDNA Reverse Transcription kit (Applied Biosystems, USA) using Labnet, Multigene thermocycler according to the manufacturer's instructions. Relative levels of mRNA were determined from cDNA by real-time PCR (Applied Biosystems-Real-Time PCR Detection System) with Power SYBR Green PCR kit (Applied Biosystems, UK) according to the manufacturer's instructions. Following normalization to the reference gene GAPDH, quantification of gene expression was carried out using a comparative $\mathrm{Ct}$ method, where $\Delta \mathrm{Ct}$ is the difference between the CT values of the target and the reference gene, and fold induction was performed from the control (Cont) for the same time point. Primers (Supplementary Table 1 in Supplementary Material available online at http://dx.doi.org/10.1155/2016/9378081) were obtained from Applied Biosystems (USA) as TAQMAN primers, or previously published primers were used (see Supplementary Table 1).

2.14. DNA Microarray Global Gene Expression Analysis. Four hundred ng of total RNA was used as input for generating biotin-labeled cRNA (Ambion, Austin, TX, United States). cRNA samples were then hybridized onto Illumina ${ }^{\circledR}$ human-8 BeadChips version 3. Hybridization, washing, Cy3streptavidin staining, and scanning were performed on the Illumina BeadStation 500 platform (Illumina, San Diego, CA, USA), according to the manufacturer's instructions, and everything was done in triplicate. Expression data analysis was carried out using the Partek ${ }^{\circledR}$ genomic suite software. Raw data were background-subtracted, normalized using the "rank invariant" algorithm, and filtered for significant expression on the basis of negative control beads. Genes were considered significantly expressed with detection $p$ values $\leq 0.01$. Differential expression analysis was performed with the Illumina custom method using freshly isolated primary hBMSC (used at passage 3 ) as a reference control. The following parameters were set to identify statistical significance: differential $p$ values $\leq 0.01$; fold change ratio $>$ 1.5. Pathway analysis was performed using DAVID Bioinformatics Resources 6.7 (http://david.abcc.ncifcrf.gov/) and GeneSpring GX software (Agilent Technologies). Pathway analysis for CL1 OS D14 versus CL2 OS D14 was conducted using the Single Experiment Pathway analysis feature in GeneSpring 12.0 (Agilent Technologies).

2.15. Small Interfering (si)RNA Transfection. For transfection, hBMSC in logarithmic growth phase were transfected with Silencer Select Predesigned ALP siRNA (25 nM) (Assay ID; s1298 and Cat number 4390824) (Ambion, The RNA Company, USA) using Lipofectamine RNAiMAX Reagent (Invitrogen, CA, USA) plus serum-free Opti-MEM ${ }^{\circledR} \mathrm{I}$ medium under the conditions described by the manufacturer. At day 3 of transfection, the cells were induced for osteogenic differentiation for an additional 7 days. ALP staining was used as a control for the siRNA transfection efficiency and timeline.

2.16. Statistical Analysis. All of the results were presented as the mean and standard deviation (SD) of at least 3 independent experiments, with 3-5 technical repeats in each experiment. Student's $t$-test (two-tailed) was used for testing differences between groups. $p$ value $<0.05$ was considered statistically significant.

\section{Results}

3.1. Comparison between CL1 and CL2: Differences in Morphology, Proliferation, and Marker Expression Profile. We isolated two distinct clonal cell populations of hBMSC-TERT: hBMSC-CL1 and hBMSC-CL2 (for easiness will be termed hereafter CL1 and CL2) based on differences in cell morphology (Figure 1(a)). CL1 cells had cuboidal morphology whereas CL2 cells have spindle-shaped fibroblast-like morphology. CL1 cells had higher proliferation rate compared to CL2 (Figure 1(b)): mean PD rates of CL1 and CL2 were 0.714 and $0.429 \mathrm{PD} /$ day, respectively (Figure $1(\mathrm{~b})$ ). Both CL1 and CL2 expressed surface marker profiles characteristics of hBMSC (>90\%): CD44+, CD63+, CD73+, CD105+, and CD166+ (Figure 1(c)). However CL1 cells showed higher expression of CD146 (92.7\% versus 12\%) and ALP (98\% versus 0\%) compared to CL2 (Figure 1(d)). TEM revealed the presence of abundant pseudopodia in CL1 indicating high motility (Figure $1(\mathrm{e})(\mathrm{A})$ ) as well as well-developed mitochondria and rough endoplasmic reticulum (rER) suggesting high metabolic activity. CL2 cells contained abundant phagocytic vacuole (pv), microvilli (mi), and lysosomes (ly) (Figure 1(e)).

We performed quantitative real-time PCR (RT-PCR) for genes expressed in mesodermal progenitor cells [12]. CL1 expressed higher levels of BMP4, MIXL1, WNT3a, and TWIST compared to CL2 (Figure 1(f), $p<0.01$ ). In contrast, CL2 expressed higher levels of Kinase Insert Domain Receptor (Type III Receptor Tyrosine Kinase) (KDR) expressed in endothelial cells and smooth muscle myosin heavy chain gene (smMHC) expressed in smooth muscle cells (Figure 1(f)).

\subsection{CL1 Cells Exhibit Enhanced Osteoblast Differentiation.} Following osteoblast (OB) differentiation induction, ALP staining and ALP enzymatic activity were significantly higher in CL1 compared to CL2 cells (Figure 2(a), $p<0.01$ ). Similarly, Alizarin Red staining and quantitation of formed mineralized matrix were more pronounced in CL1 cells (Figure $2(\mathrm{~b}), p<0.01)$. In addition, CL1 cells expressed higher levels of osteoblastic genes, ALP, RUNX2, and osteopontin (OPN) (Figure 2(c) upper panel) compared to CL2 cells.

Global gene expression microarray analysis of $\mathrm{OB}$ differentiated cells at day 14 showed around 1060 genes significantly upregulated more than 2-fold $(p<0.01)$ in CL1. Among the upregulated genes, 80 genes were annotated to bone development and osteoblast differentiation (Table 1). The highest upregulated genes included paired-like homeodomain 2 (PITX2), Insulin-like growth factor 1 (IGF1) and 

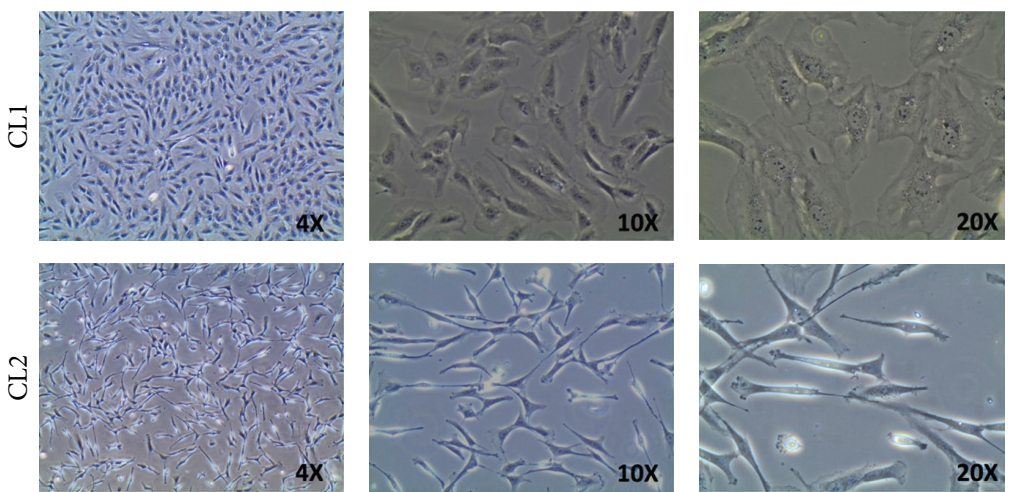

(a)
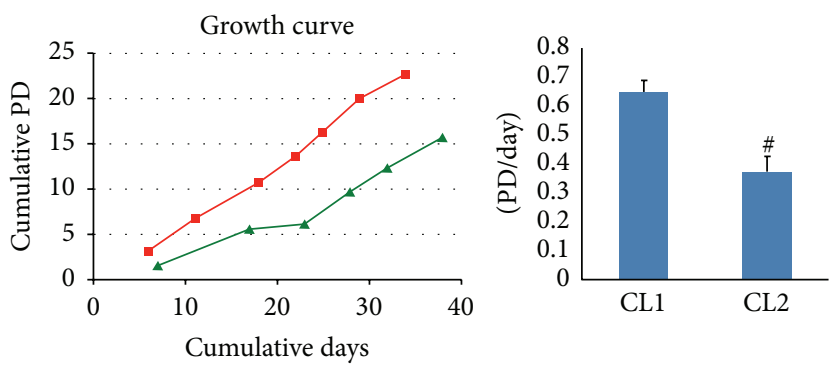

$\rightarrow \mathrm{CL} 1 \leadsto \mathrm{CL} 2$

(b)
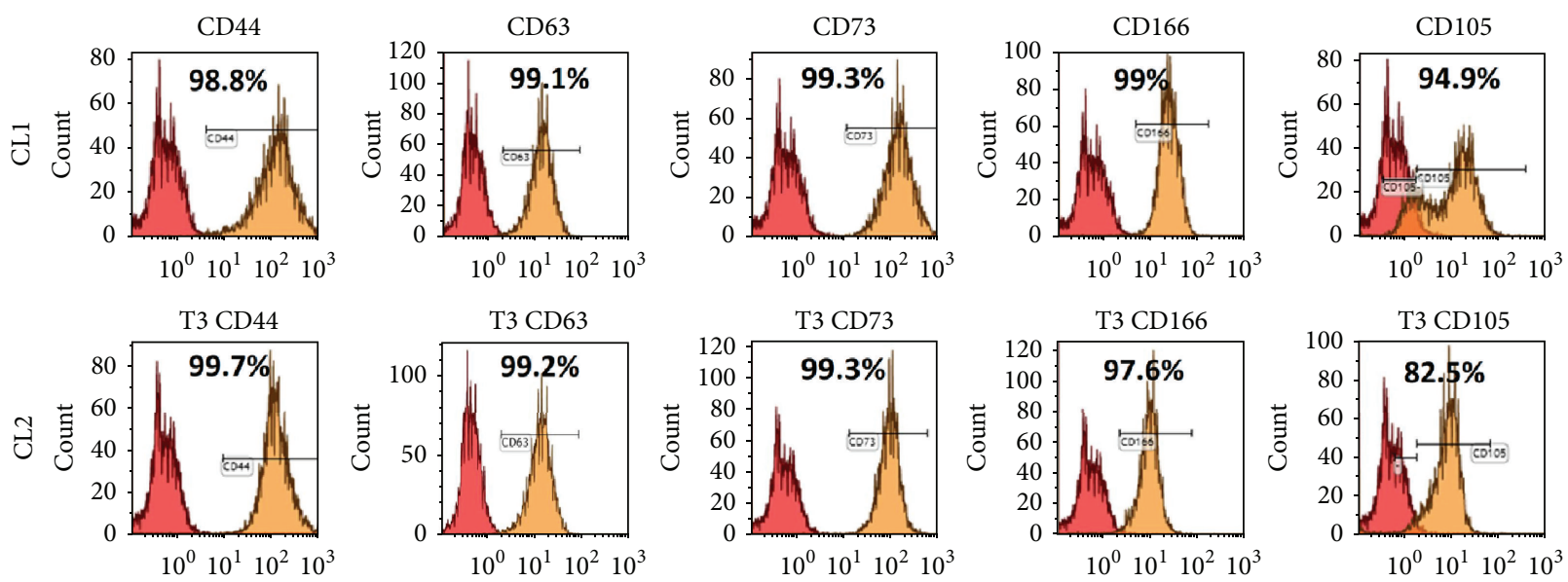

(c)
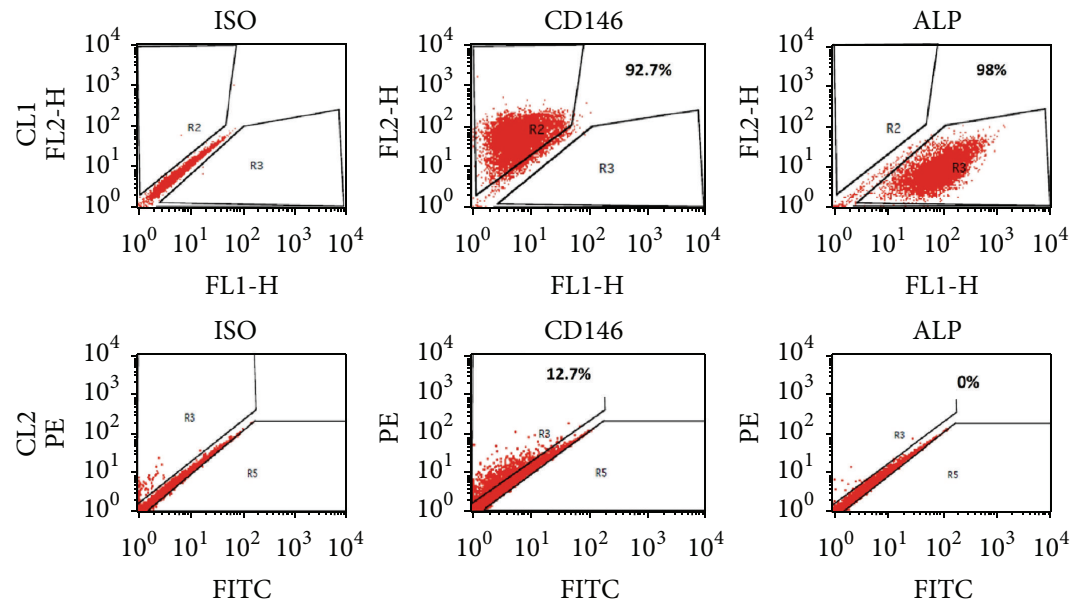

(d)

FIgure 1: Continued. 


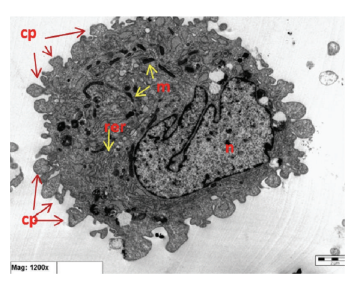

(A)

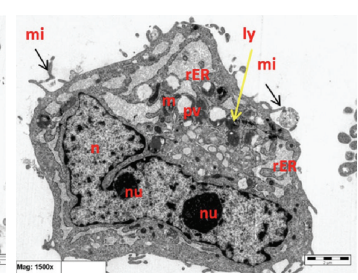

(B)
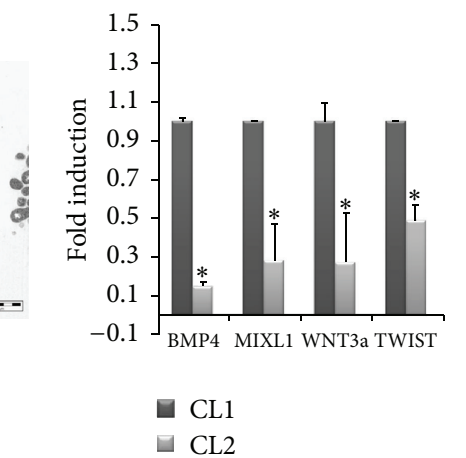

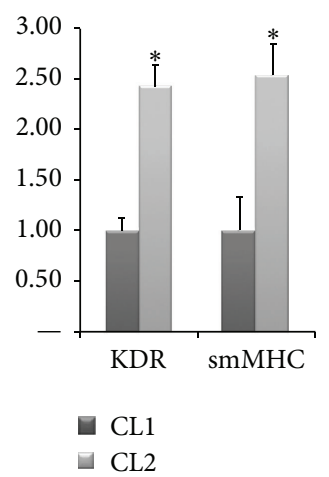

(f)

FIGURE 1: Cellular phenotype of two clonal populations of human bone marrow stromal stem cells: CL1 and CL2. (a) Cell morphology. CL1 cells showed large cuboidal morphology while CL2 cells had spindle-shaped fibroblast-like morphology. (b) Growth curves showing population doubling (PD) rate during long term culture. (c) Flow cytometry analysis (FACS) shows expression of CD44, CD63, CD73, CD105, and CD166 in CL1 and CL2 cells. Matched isotype control was used for gating. (d) Flow cytometry analysis presented as dot blot of CD146 and alkaline phosphatase (ALP) cell surface proteins. (e) Transmission electron microscope (TEM). (A): CL1 (1200x); (B): CL2 (1500x). n: nucleus, nu: nucleolus, rER: rough endoplasmic reticulum, ly: lysosomes, pv: phagocytic vacuole, and rer: reticular stalk of rER. (f) Gene expression analysis using RT-PCR for a group of mesodermal and stromal genes. Gene expression was normalized to GAPDH and presented as fold change. Data is shown as mean \pm SD of three independent experiments. ${ }^{*} p<0.05$; ${ }^{*} p<0.001$.

collagen, type V, alpha 3 (COL5A3), osteomodulin (OMD), and T-box 15 (TBX15) (Table 1). Furthermore, several known osteoblast-related genes were upregulated in CL1 cells such as bone morphogenetic protein 6 (BMP6), fibroblast growth factor receptor 3 (FGFR3), insulin-like growth factor binding protein 5 (IGFBP5), and vitamin D (1,25-dihydroxyvitamin D3) receptor (VDR) (Table 1). On the other hand, 1200 genes were upregulated in CL2 cells: 255 genes were annotated to immunity and immune response and defense. This category included genes from, complement system, chemokine (C-C motif) ligands, interferon family, chemokine (C-X-C motif) ligands, and receptor, major histocompatibility complex class II molecules, interleukins, and tumor necrosis factor receptor superfamily (Table 2 and Supplementary Table 3).

\subsection{CL1 Cells Exhibit Enhanced Adipocyte Differentiation.}

We observed significant differences between CL1 and CL2 in their response to adipocytic differentiation induction. CL1 differentiated readily to adipocytes compared to CL2 (Figure 2(d), lower panel) evidenced by higher levels of adipocytic markers gene expression, LPL (lipoprotein lipase), and adiponectin, as well as formation of mature lipid filled adipocytes visualized by Oil Red-O staining and quantitative Nile red staining (Figure 2(d)).

3.4. CL1 Cells Differentiate to Chondrocytic Lineage. In pellet cultures, CL1 cells formed 3D pellets containing proteoglycan-secreting chondrocytes, which stained positive with Alcian blue. Limited chondrocyte differentiation was visible in cell pellets of CL2 cells. The differentiated chondrocytes in CL1 pellets expressed higher levels of collagen X and collagen II, which was overlapping the Alcian blue stain (Figure 2(e)).

3.5. Molecular Signature of CL1 and CL2 Cells. To define the molecular signature and molecular differences between CL1 and CL2, we compared the basal gene expression pattern of CL1 and CL2 cells using DNA microarrays. The PCA analysis showed a clear separation between CL1 and CL2 (Supplementary Figure 1). Comparison between CL1 with CL2 showed that 915 genes were differentially expressed in the two cell lines ( $>2$-fold, $p<0.01$ ): 462 genes were upregulated, and 452 were downregulated in CL1 versus CL2. The most relevant genes that were upregulated in CL1 are listed in Table 3(a). Among these 35 highly expressed genes in CL1, the following 11 genes were present in skeletal and muscular system development and function: FOLR3, CCL3L1, SERPINB2, POSTN, IGFBP5, CCL3, NOV, ALP, TNFRSF11B, ACTG2, and CDH11 (Table 3(a)). Functional annotation of the upregulated genes in CL1 using the Ingenuity Pathway Analysis (IPA) revealed enrichment in the following categories: "tissue development," "skeletal and muscular system development and function," and "organismal development" (Table 3(b)). Furthermore, the DAVID annotation tool was employed to assess the functional relationships of the upregulated genes in CL1 showing enrichment in ontologies: "skeletal and muscular system development and function" that included bone size, osteoblast differentiation, bone mineralization, and bone mineral density (Table 3(c)). CL1 exhibited upregulation of WNT pathway ligands: WNT5B (2-fold) and LRP5 (2-fold) (Table 1). Also, ALP was among the highly expressed genes together with POSTN, IGFBP5, SPP1, IL6, and DKK1 (Tables 3(a) and 1). These genes are known to play an important role in osteoblast differentiation and bone formation. For CL2, inhibitors of WNT pathway were upregulated and included SFRP1 (11-fold), DKK2 (3.2-fold), FGF2 (3.1-fold), and GBP2 (2.4-fold). Functional annotation of the upregulated genes in CL2 revealed enrichment in the following categories: "developmental process," "multicellular organismal process," "biological adhesion," and "immune system process" (Supplementary Table 2A). In-depth analysis 


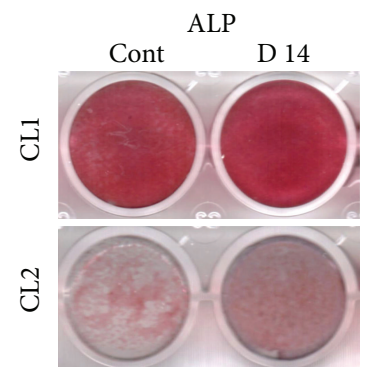

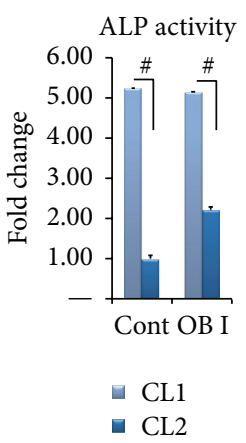

(a)
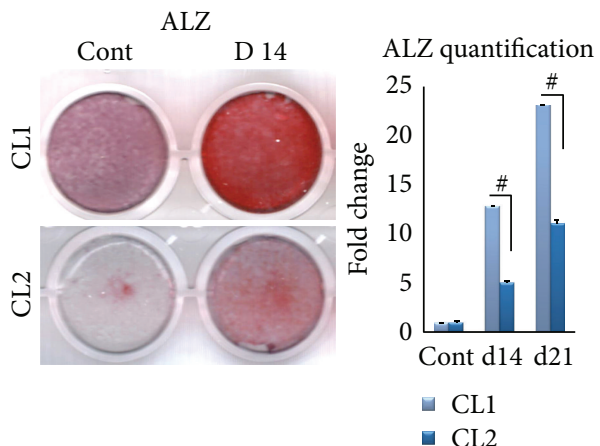

(b)
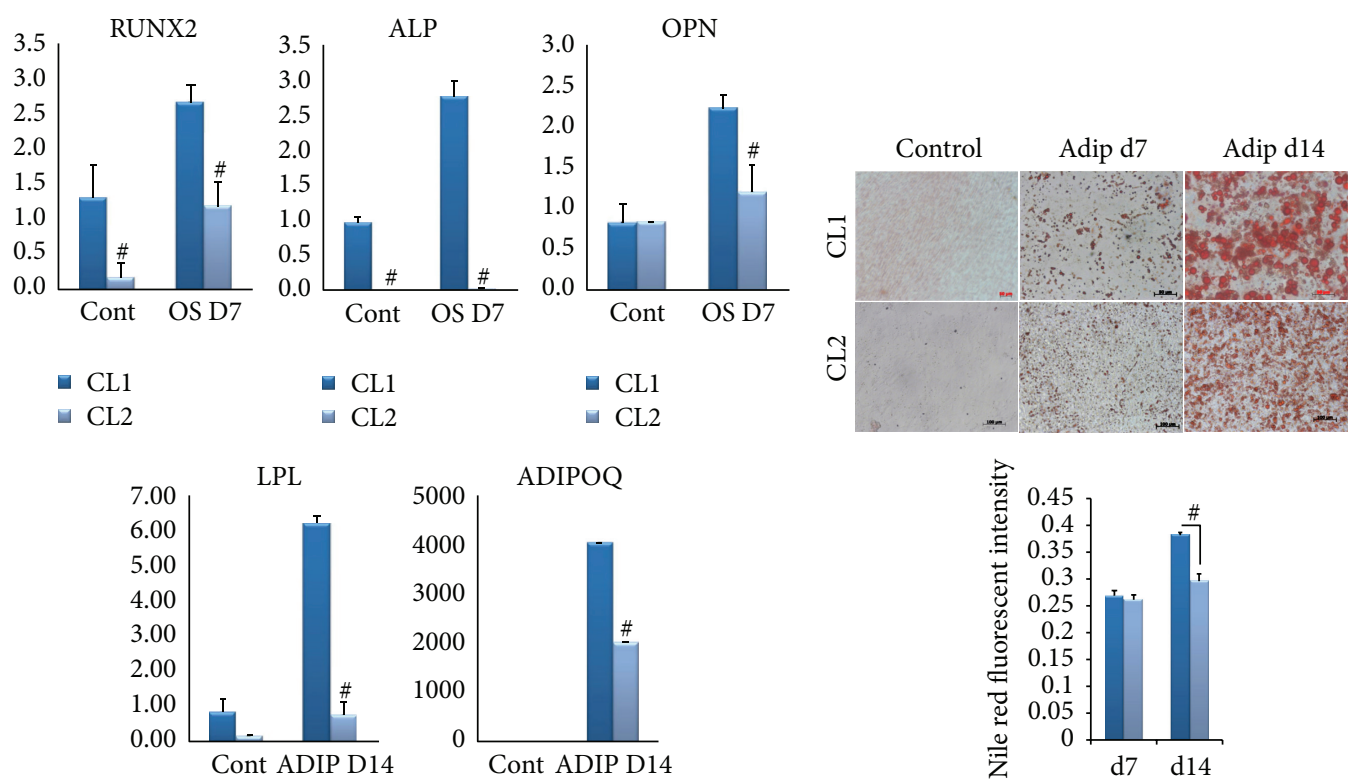

- CL1

CL1

- CL2

- CL2

(c)

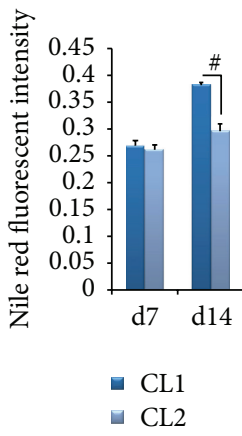

(d)

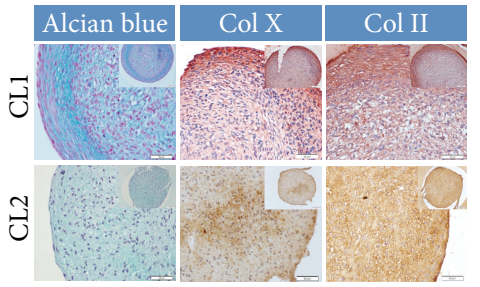

(e)

FIGURE 2: In vitro osteoblastic and adipocytic differentiation of two clonal populations of human bone marrow stromal stem cells: CL1 and CL2 cells. Both cell lines were induced for osteoblast differentiation using standard protocol described in the Methods. (a) ALP staining at day 14 in control noninduced (Cont) and osteoblast induced cells (D14). Right panel shows ALP activity $(n=3$ independent experiments, ${ }^{\#} p<0.001$ ). (b) Mineralized matrix formation visualized by Alizarin Red S staining. Right panel shows Alizarin Red quantification at day 14 and 21 after osteoblast differentiation ( $n=3$ independent experiments, ${ }^{*} p<0.001$ ). (c) Quantitative RT-PCR of osteoblastic and adipocyte gene markers in CL1 and CL2 during osteoblast (upper panel) and adipocyte (lower panel) differentiation. ALP = alkaline phosphatase, $\mathrm{OPN}=$ osteopontin, $\mathrm{LPL}=$ lipoprotein lipase, and ADIPOQ $=$ adiponectin. Data are presented as fold change in expression of each target gene normalized to GAPDH ( $n=3$ independent experiments, $\left.p<0.05 ;{ }^{*} p<0.001\right)$. (d) CL1 and CL2 lines were induced for adipocyte differentiation using standard protocol described in the Methods. Adipocyte formation was visualized at day 7 (Adip d7) and day 14 (Adip d14) by Oil Red-O staining. Lower panel presents quantification of Nile red staining ( $n=3$ independent experiments, $\left.{ }^{\#} p<0.001\right)$. (e) CL1 and CL2 lines were induced for chondrocyte differentiation using 21-day pellet culture method as described in the Methods. The pellets were stained with Alcian blue, collagen 10 (Col X), and collagen 2 (Col II) (original magnification 5x). 
TABLE 1: Microarray data analysis showing genes related to bone development and osteoblast differentiation upregulated in CL1 versus CL2 cells.

\begin{tabular}{|c|c|c|c|c|}
\hline Probe ID & Genbank accession & Gene name & Gene symbol & FC \\
\hline A_23_P167367 & NM_153426 & Paired-like homeodomain 2 & PITX2 & 308.84 \\
\hline A_23_P13907 & NM_000618 & $\begin{array}{l}\text { Insulin-like growth factor } 1 \text { (somatomedin } \\
\text { C) }\end{array}$ & IGF1 & 118.00 \\
\hline A_23_P55749 & NM_015719 & Collagen, type V, alpha 3 & COL5A3 & 75.11 \\
\hline A_23_P94397 & NM_005014 & Osteomodulin & OMD & 56.07 \\
\hline A_24_P128442 & NM_152380 & T-box 15 & TBX15 & 54.38 \\
\hline A_33_P3708413 & NM_003480 & Microfibrillar associated protein 5 & MFAP5 & 53.73 \\
\hline A_24_P72064 & NM_000163 & Growth hormone receptor & GHR & 51.47 \\
\hline A_23_P215454 & NM_001278939 & Elastin & ELN & 50.15 \\
\hline A_24_P200854 & NM_006735 & Homeobox A2 & HOXA2 & 44.99 \\
\hline A_23_P19624 & NM_001718 & Bone morphogenetic protein 6 & BMP6 & 41.43 \\
\hline A_23_P500501 & NM_000142 & Fibroblast growth factor receptor 3 & FGFR3 & 33.95 \\
\hline A_23_P154605 & NM_018837 & Sulfatase 2 & SULF2 & 29.57 \\
\hline A_23_P28815 & NM_000782 & $\begin{array}{l}\text { Cytochrome P450, family 24, subfamily A, } \\
\text { polypeptide } 1\end{array}$ & CYP24A1 & 22.47 \\
\hline A_23_P210109 & NM_019885 & $\begin{array}{l}\text { Cytochrome P450, family } 26 \text {, subfamily B, } \\
\text { polypeptide } 1\end{array}$ & CYP26B1 & 22.42 \\
\hline A_23_P323180 & NM_006898 & Homeobox D3 & HOXD3 & 21.08 \\
\hline A_32_P405759 & NM_152888 & Collagen, type XXII, alpha 1 & COL22A1 & 20.36 \\
\hline A_33_P3363799 & NM_001242607 & Neural cell adhesion molecule 1 & NCAM1 & 17.33 \\
\hline A_33_P3381378 & NM_001257096 & Paired box 1 & PAX1 & 17.12 \\
\hline A_23_P383009 & NM_000599 & Insulin-like growth factor binding protein 5 & IGFBP5 & 14.67 \\
\hline A_33_P3382856 & NM_133507 & Decorin & $\mathrm{DCN}$ & 14.38 \\
\hline A_23_P10206 & NM_005328 & Hyaluronan synthase 2 & HAS2 & 14.33 \\
\hline A_24_P77904 & NM_018951 & Homeobox A10 & HOXA10 & 13.64 \\
\hline A_23_P2814 & NM_005905 & SMAD family member 9 & SMAD9 & 12.45 \\
\hline A_23_P88404 & NM_003239 & Transforming growth factor, beta 3 & TGFB3 & 12.11 \\
\hline A_32_P4595 & NM_000337 & $\begin{array}{l}\text { Sarcoglycan, delta ( } 35 \mathrm{kDa} \\
\text { dystrophin-associated glycoprotein) }\end{array}$ & SGCD & 8.95 \\
\hline A_23_P162171 & NM_006500 & Melanoma cell adhesion molecule & MCAM & 8.60 \\
\hline A_24_P38276 & NM_003505 & Frizzled class receptor 1 & FZD1 & 7.81 \\
\hline A_23_P24129 & NM_012242 & $\begin{array}{l}\text { Dickkopf WNT signaling pathway inhibitor } \\
1\end{array}$ & DKK1 & 7.04 \\
\hline A_33_P3264528 & NM_005523 & Homeobox A11 & HOXA11 & 6.64 \\
\hline A_33_P3220470 & NM_005585 & SMAD family member 6 & SMAD6 & 6.47 \\
\hline A_23_P23783 & NM_000261 & $\begin{array}{l}\text { Myocilin, trabecular meshwork inducible } \\
\text { glucocorticoid response }\end{array}$ & MYOC & 6.41 \\
\hline A_33_P3263432 & NM_003637 & Integrin, alpha 10 & ITGA10 & 6.35 \\
\hline A_23_P383009 & NM_000599 & Insulin-like growth factor binding protein 5 & IGFBP5 & 6.18 \\
\hline A_33_P3219090 & NM_005542 & Insulin induced gene 1 & INSIG1 & 5.78 \\
\hline A_23_P162589 & NM_001017535 & $\begin{array}{l}\text { Vitamin D (1,25-dihydroxyvitamin D3) } \\
\text { receptor }\end{array}$ & VDR & 5.68 \\
\hline A_23_P374695 & NM_000459 & TEK tyrosine kinase, endothelial & TEK & 5.65 \\
\hline A_24_P261169 & NM_006378 & $\begin{array}{l}\text { Sema domain, immunoglobulin domain } \\
\text { (Ig), transmembrane domain (TM), and } \\
\text { short cytoplasmic domain, (semaphorin) 4D }\end{array}$ & SEMA4D & 5.41 \\
\hline A_33_P3297930 & NM_005202 & Collagen, type VIII, alpha 2 & COL8A2 & 5.138 \\
\hline A_23_P206359 & NM_004360 & Cadherin 1, type 1, E-cadherin (epithelial) & $\mathrm{CDH} 1$ & 5.12 \\
\hline A_24_P264943 & NM_000095 & Cartilage oligomeric matrix protein & COMP & 5.07 \\
\hline A_33_P3214948 & NM_014767 & $\begin{array}{l}\text { Sparc/osteonectin, cwcv, and kazal-like } \\
\text { domains proteoglycan (testican) } 2\end{array}$ & SPOCK2 & 4.54 \\
\hline
\end{tabular}


TABLe 1: Continued.

\begin{tabular}{|c|c|c|c|c|}
\hline Probe ID & Genbank accession & Gene name & Gene symbol & $\mathrm{FC}$ \\
\hline A_24_P55496 & NM_053001 & Odd-skipped related transcription factor 2 & OSR2 & 4.38 \\
\hline A_24_P354689 & NM_004598 & $\begin{array}{l}\text { Sparc/osteonectin, cwcv, and kazal-like } \\
\text { domains proteoglycan (testican) } 1\end{array}$ & SPOCK1 & 4.23 \\
\hline A_23_P69030 & NM_001850 & Collagen, type VIII, alpha 1 & COL8A1 & 3.93 \\
\hline A_23_P128084 & NM_002206 & Integrin, alpha 7 & ITGA7 & 3.91 \\
\hline A_24_P3249 & NM_000965 & Retinoic acid receptor, beta & RARB & 3.91 \\
\hline A_24_P168574 & AJ224867 & GNAS complex locus & GNAS & 3.83 \\
\hline A_23_P320739 & NM_002397 & Myocyte enhancer factor $2 \mathrm{C}$ & MEF2C & 3.74 \\
\hline A_23_P429383 & NM_014213 & Homeobox D9 & HOXD9 & 3.54 \\
\hline A_23_P42322 & NM_080680 & Collagen, type XI, alpha 2 & COL11A2 & 3.42 \\
\hline A_23_P160318 & NM_001856 & Collagen, type XVI, alpha 1 & COL16A1 & 3.36 \\
\hline A_33_P3407013 & NM_000600 & Interleukin 6 & IL6 & 3.30 \\
\hline A_23_P315364 & NM_002089 & Chemokine (C-X-C motif) ligand 2 & CXCL2 & 3.29 \\
\hline A_33_P3413168 & ВС007696 & Collagen, type XXVII, alpha 1 & COL27A1 & 3.08 \\
\hline A_23_P43164 & NM_015170 & Sulfatase 1 & SULF1 & 3.05 \\
\hline A_23_P58676 & NM_001204375 & Natriuretic peptide receptor 3 & NPR3 & 3.04 \\
\hline A_33_P3290562 & NM_000168 & GLI family zinc finger 3 & GLI3 & 3.00 \\
\hline A_23_P69497 & NM_003278 & C-type lectin domain family 3 , member B & CLEC3B & 2.99 \\
\hline A_24_P353619 & NM_000478 & Alkaline phosphatase, liver/bone/kidney & ALPL & 2.99 \\
\hline A_33_P3305749 & NM_000965 & Retinoic acid receptor, beta & RARB & 2.89 \\
\hline A_23_P307328 & NM_007331 & Wolf-Hirschhorn syndrome candidate 1 & WHSC1 & 2.77 \\
\hline A_23_P152305 & NM_001797 & $\begin{array}{l}\text { Cadherin 11, type } 2 \text {, OB-cadherin } \\
\text { (osteoblast) }\end{array}$ & CDH11 & 2.77 \\
\hline A_23_P216361 & NM_021110 & Collagen, type XIV, alpha 1 & COL14A1 & 2.62 \\
\hline A_23_P7313 & NM_001040058 & Secreted phosphoprotein 1 & SPP1 & 2.60 \\
\hline A_24_P267592 & NM_015474 & SAM domain and HD domain 1 & SAMHD1 & 2.54 \\
\hline A_23_P210482 & NM_000022 & Adenosine deaminase & $\mathrm{ADA}$ & 2.52 \\
\hline A_23_P148047 & NM_000958 & Prostaglandin E receptor 4 (subtype EP4) & PTGER4 & 2.51 \\
\hline A_23_P345725 & NM_014621 & Homeobox D4 & HOXD4 & 2.47 \\
\hline A_24_P125283 & NM_001015053 & Histone deacetylase 5 & HDAC5 & 2.37 \\
\hline A_33_P3231953 & NM_004370 & Collagen, type XII, alpha 1 & COL12A1 & 2.34 \\
\hline A_24_P298027 & NM_004655 & Axin 2 & AXIN2 & 2.31 \\
\hline A_24_P336551 & NM_199173 & $\begin{array}{l}\text { Bone gamma-carboxyglutamate (gla) } \\
\text { protein }\end{array}$ & BGLAP & 2.29 \\
\hline A_33_P3313825 & XM_006713316 & $\begin{array}{l}\text { Transforming growth factor, beta receptor II } \\
(70 / 80 \mathrm{kDa})\end{array}$ & TGFBR2 & 2.23 \\
\hline A_23_P82990 & NM_033014 & Osteoglycin & OGN & 2.20 \\
\hline A_32_P24585 & NM_001017995 & SH3 and PX domains $2 \mathrm{~B}$ & SH3PXD2B & 2.20 \\
\hline A_24_P944458 & NM_016133 & Insulin induced gene 2 & INSIG2 & 2.14 \\
\hline A_23_P99063 & NM_002345 & Lumican & LUM & 2.12 \\
\hline A_32_P5251 & NM_001024809 & Retinoic acid receptor, alpha & RARA & 2.11 \\
\hline A_24_P935491 & NM_000090 & Collagen, type III, alpha 1 & COL3A1 & 2.10 \\
\hline A_33_P3312104 & NM_025099 & $\begin{array}{l}\text { CTS telomere maintenance complex } \\
\text { component } 1\end{array}$ & CTC1 & 2.06 \\
\hline A_33_P3321342 & NM_016133 & Insulin induced gene 2 & INSIG2 & 2.04 \\
\hline A_23_P100486 & NM_206824 & $\begin{array}{l}\text { Vitamin K epoxide reductase complex, } \\
\text { subunit } 1\end{array}$ & VKORC1 & 2.02 \\
\hline A_23_P53588 & NM_030775 & $\begin{array}{l}\text { Wingless-type MMTV integration site } \\
\text { family, member } 5 B\end{array}$ & WNT5B & 2.00 \\
\hline A_23_P616356 & NM_001291902 & $\begin{array}{l}\text { Low density lipoprotein receptor-related } \\
\text { protein } 5\end{array}$ & LRP5 & 2.00 \\
\hline
\end{tabular}


TABLE 2: Microarray data analysis showing genes related immune modulation and immune defense genes upregulated in CL2 versus CL1 cells.

\begin{tabular}{|c|c|c|c|}
\hline ID & Gene name & Gene symbol & Fold change \\
\hline A_23_P128094 & ATP-binding cassette, subfamily B (MDR/TAP), member 9 & АВСB9 & 2.1 \\
\hline A_32_P156963 & Actin, gamma 1 & ACTG1 & 3.0 \\
\hline A_23_P28279 & ARP1 actin related protein 1 homolog B, centractin beta (yeast) & ACTR1B & 2.0 \\
\hline A_23_P211207 & Adenosine deaminase, RNA-specific, B1 & ADARB1 & 3.5 \\
\hline A_23_P381261 & Adenylate cyclase 4 & ADCY4 & 5.0 \\
\hline A_23_P169993 & Adenylate cyclase 8 (brain) & ADCY8 & 3.2 \\
\hline A_23_P76823 & Adenylosuccinate synthase-like 1 & ADSSL1 & 7.0 \\
\hline A_23_P135486 & Alpha hemoglobin stabilizing protein & AHSP & 2.6 \\
\hline A_23_P216023 & Angiopoietin 1 & ANGPT1 & 7.6 \\
\hline A_23_P94501 & Annexin A1 & ANXA1 & 2.6 \\
\hline A_23_P121716 & Annexin A3 & ANXA3 & 346.8 \\
\hline A_23_P6398 & Adaptor-related protein complex 1 , beta 1 subunit & AP1B1 & 2.2 \\
\hline A_23_P120931 & $\begin{array}{l}\text { Apolipoprotein B mRNA editing enzyme, catalytic polypeptide-like } \\
\text { 3C }\end{array}$ & APOBEC3C & 2.2 \\
\hline A_23_P132316 & $\begin{array}{l}\text { Apolipoprotein B mRNA editing enzyme, catalytic polypeptide-like } \\
\text { 3D }\end{array}$ & APOBEC3D & 2.4 \\
\hline A_23_P357101 & $\begin{array}{l}\text { Apolipoprotein B mRNA editing enzyme, catalytic polypeptide-like } \\
3 \mathrm{~F}\end{array}$ & APOBEC3F & 2.3 \\
\hline A_23_P143713 & $\begin{array}{l}\text { Apolipoprotein B mRNA editing enzyme, catalytic polypeptide-like } \\
3 \mathrm{G}\end{array}$ & APOBEC3G & 9.6 \\
\hline A_23_P93988 & Rho guanine nucleotide exchange factor (GEF) 5 & ARHGEF5 & 8.7 \\
\hline A_24_P20383 & Actin related protein $2 / 3$ complex, subunit $4,20 \mathrm{kDa}$ & ARPC4 & 2.2 \\
\hline A_23_P208389 & AXL receptor tyrosine kinase & AXL & 2.0 \\
\hline A_33_P3279353 & Azurocidin 1 & AZU1 & 4.8 \\
\hline A_33_P3262043 & BCL2-associated agonist of cell death & BAD & 2.3 \\
\hline A_24_P159648 & BAIl-associated protein 2 & BAIAP2 & 2.2 \\
\hline A_23_P370682 & Basic leucine zipper transcription factor, ATF-like 2 & BATF2 & 22.2 \\
\hline A_23_P160720 & Basic leucine zipper transcription factor, ATF-like 3 & BATF3 & 3.0 \\
\hline A_33_P3229272 & Breast cancer antiestrogen resistance 1 & BCAR1 & 3.3 \\
\hline A_23_P210886 & BCL2-like 1 & BCL2L1 & 3.4 \\
\hline A_23_P98350 & Baculoviral IAP repeat containing 3 & BIRC3 & 25.0 \\
\hline A_23_P31725 & B lymphoid tyrosine kinase & BLK & 7.3 \\
\hline A_33_P3419785 & BCL2/adenovirus E1B $19 \mathrm{kDa}$ interacting protein 3 & BNIP3 & 7.3 \\
\hline A_19_P00802936 & BRICK1, SCAR/WAVE actin-nucleating complex subunit & BRK1 & 2.2 \\
\hline A_23_P2431 & Complement component 3 a receptor 1 & C3AR1 & 2.6 \\
\hline A_23_P97541 & Complement component 4 binding protein, alpha & C4BPA & 2.6 \\
\hline A_23_P92928 & Complement component 6 & C6 & 4.0 \\
\hline A_23_P213857 & Complement component 7 & $\mathrm{C} 7$ & 2.2 \\
\hline A_33_P3745146 & Cell adhesion molecule 1 & CADM1 & 34.3 \\
\hline A_23_P250347 & Calcium/calmodulin-dependent protein kinase IV & CAMK4 & 3.4 \\
\hline A_23_P253791 & Cathelicidin antimicrobial peptide & CAMP & 3.3 \\
\hline A_23_P82324 & Caspase recruitment domain family, member 11 & CARD11 & 7.9 \\
\hline A_23_P500433 & Caspase recruitment domain family, member 9 & CARD9 & 2.4 \\
\hline A_23_P202978 & Caspase 1, apoptosis-related cysteine peptidase & CASP1 & 2.4 \\
\hline A_23_P123853 & Chemokine (C-C motif) ligand 19 & CCL19 & 2.0 \\
\hline A_23_P17065 & Chemokine (C-C motif) ligand 20 & CCL20 & 14.6 \\
\hline A_23_P215484 & Chemokine (C-C motif) ligand 26 & CCL26 & 2.8 \\
\hline A_23_P503072 & Chemokine (C-C motif) ligand 28 & CCL28 & 4.3 \\
\hline A_33_P3316273 & Chemokine (C-C motif) ligand 3 & CCL3 & 2.3 \\
\hline
\end{tabular}


TABLE 2: Continued.

\begin{tabular}{|c|c|c|c|}
\hline ID & Gene name & Gene symbol & Fold change \\
\hline A_23_P152838 & Chemokine (C-C motif) ligand 5 & CCL5 & 2.7 \\
\hline A_23_P78037 & Chemokine (C-C motif) ligand 7 & CCL7 & 16.0 \\
\hline A_23_P207456 & Chemokine (C-C motif) ligand 8 & CCL8 & 2.8 \\
\hline A_23_P361773 & Cyclin D3 & CCND3 & 2.3 \\
\hline A_33_P3284508 & CD14 molecule & CD14 & 4.2 \\
\hline A_23_P259863 & CD177 molecule & CD177 & 2.7 \\
\hline A_33_P3381513 & CD274 molecule & $\mathrm{CD} 274$ & 10.8 \\
\hline A_23_P15369 & CD300 molecule-like family member b & CD300LB & 2.0 \\
\hline A_23_P416747 & CD3e molecule, epsilon (CD3-TCR complex) & CD3E & 2.7 \\
\hline A_24_P188377 & $\begin{array}{l}\text { CD55 molecule, decay accelerating factor for complement (Cromer } \\
\text { blood group) }\end{array}$ & CD55 & 5.9 \\
\hline A_23_P300056 & Cell division cycle 42 & $\mathrm{CDC} 42$ & 4.5 \\
\hline A_32_P148710 & Cofilin 1 (nonmuscle) & CFL1 & 2.8 \\
\hline A_33_P3217584 & Cholinergic receptor, nicotinic, alpha 4 (neuronal) & CHRNA4 & 2.9 \\
\hline A_33_P3415300 & Complexin 2 & CPLX2 & 2.7 \\
\hline A_23_P133408 & Colony stimulating factor 2 (granulocyte-macrophage) & CSF2 & 16.5 \\
\hline A_33_P3396139 & Cytotoxic T-lymphocyte-associated protein 4 & CTLA4 & 3.0 \\
\hline A_33_P3287631 & Cathepsin B & CTSB & 2.3 \\
\hline A_33_P3283480 & Cathepsin C & CTSC & 8.2 \\
\hline A_23_P7144 & $\begin{array}{l}\text { Chemokine (C-X-C motif) ligand } 1 \text { (melanoma growth stimulating } \\
\text { activity, alpha) }\end{array}$ & CXCL1 & 6.5 \\
\hline A_33_P3712341 & Chemokine (C-X-C motif) ligand 12 & CXCL12 & 4.8 \\
\hline A_33_P3351249 & Chemokine (C-X-C motif) ligand 16 & CXCL16 & 11.6 \\
\hline A_23_P315364 & Chemokine (C-X-C motif) ligand 2 & CXCL2 & 3.3 \\
\hline A_24_P183150 & Chemokine (C-X-C motif) ligand 3 & CXCL3 & 2.9 \\
\hline A_23_P155755 & Chemokine (C-X-C motif) ligand 6 & CXCL6 & 5.0 \\
\hline A_33_P3214550 & Chemokine (C-X-C motif) receptor 2 & CXCR2 & 2.0 \\
\hline A_33_P3389230 & Chemokine (C-X-C motif) receptor 3 & CXCR3 & 2.3 \\
\hline
\end{tabular}

of the biological processes revealed several immune-related pathways: "MAPKKK cascade," "immunity and defense," "signal transduction," "extracellular matrix protein-mediated signaling," and "interferon-mediated immunity," among others that were upregulated (Supplementary Table 2B). Also, 40 genes related to immune system related factors were identified as significantly enriched in CL2 compared to CL1 cells (Supplementary Table 2C). We chose the following genes for validation of the microarray results: NOV, IGFBP5, ALP, TAGLN, and CDH11 as they were highly expressed in CL1. RT-PCR analysis confirmed the microarray results (Figure 3 ).

Furthermore, we compared the molecular phenotype of CL1 and CL2 cells with that of phBMSC. We found that more than $80 \%$ of the genes expressed in CL1 and 90\% in CL2 cells were common with primary phBMSC (Supplementary Figure 2), suggesting that CL1 and CL2 molecular phenotype exist within the heterogeneous population of phBMSC cultures.

3.6. ALP Knockdown Impairs Differentiation of CL1 Cells. Since ALP has been suggested as a marker for hBMSC progenitor cell lineage commitment [13] and was highly upregulated in CL1 cells, we tested its biological role in
CL1 cells. ALP siRNA transfection decreased ALP protein level, ALP activity, and mRNA gene expression compared to control cells transfected with control siRNA $(p<0.01)$ and this inhibition was detectable up to day 7 days after osteoblast differentiation induction (Figures 4(A) and 4(B)). At day 14 of differentiation, mineralization ability of CL1 was significantly impaired (Figure 4(C)). In addition, we found that the number of mature adipocyte formations was significantly reduced to more than $75 \%(p<0.01)$ (Figure $4(\mathrm{D})$ ).

To identify relevant adipocyte differentiation associated genes that were targeted by ALP deficiency, we compared the downregulated genes of ALP deficient CL1 with the upregulated genes identified during adipocytic differentiation of CL1. We identified 62 genes that were common (Figure 5(a), Table 4) and among these genes were genes related to metabolism (primarily lipid and carbohydrate) and transport including CYB5B, CHST1, TAP1, ATP8A1, LRP8, PLCD1, and FABP5 (Table 4). We further performed quantitative real-time PCR of ALP deficient CL1 cells during adipocyte differentiation. The following adipocyte-associated genes were downregulated: PPAR $\gamma 2$, LPL, and aP2 (Figure 5(b)), 
TABLE 3: Whole genome microarray analysis of two clonal populations of human bone marrow stromal stem cells: CL1 and CL2 cells. (a) Top 35 highly upregulated genes in CL1 cells versus CL2 cells. (b) Ingenuity ${ }^{\circledR}$ Pathway Analysis (IPA ${ }^{\circledR}$ ) showing the different physiological system development and function genes found in each category and the corresponding $p$ value. (c) Upper part IPA analysis showing the categories for skeletal and muscular system development and function upregulated in CL1 cells and lower part showing genes upregulated in CL2 cells. NOV = nephroblastoma overexpressed, IGFBP5 = insulin-like growth factor binding protein 5, ALP, TAGLN $=$ transgelin, and CDH11 = OB-cadherin (osteoblast).

(a)

\begin{tabular}{lc}
\hline Gene ID & Fold change CL1 versus CL2 \\
\hline FOLR3 & 28.4721 \\
CCL3L3 & 17.936 \\
POSTN & 15.5924 \\
SERPINB2 & -17.2599 \\
IGFBP5 & 14.6708 \\
CCL3 & 13.1203 \\
NOV & 11.2921 \\
ACTG2 & 10.4493 \\
CRYAB & 10.0678 \\
PSG4 & 9.68913 \\
RAB3IL1 & 9.16897 \\
SCIN & 9.13702 \\
MYL9 & 9.12814 \\
TNFRSF11B & 8.86049 \\
TAGLN & 8.75581 \\
CDH12 & 8.06682 \\
SHISA2 & 8.0291 \\
THBS1 & 7.86854 \\
SPP1 & 7.64205 \\
LCE2A & 7.41042 \\
TMEM98 & 7.38011 \\
PSG7 & 7.12183 \\
MYPN & 7.01837 \\
FNDC1 & 6.88102 \\
TNS3 & 6.72083 \\
ABI3BP & 6.67822 \\
LRP3 & 6.64307 \\
MMP3 & 6.34715 \\
FAM167A & 6.02684 \\
HSPB2 & 6.01063 \\
ALPL & 6.01022 \\
CTSK & 5.87356 \\
CXCL12 & 5.68572 \\
THY1 & 4.89445 \\
CDH10 & 4.86105 \\
\hline &
\end{tabular}

(b)

\begin{tabular}{lcc}
\hline Name & p value & \# molecules \\
\hline \multicolumn{2}{c}{ Physiological system development and function } \\
Organismal development & $7.05 E-10-1.43 E-03$ & 181 \\
Embryonic development & $1.00 E-09-1.43 E-03$ & 154 \\
Organ development & $1.00 E-09-1.43 E-03$ & 145 \\
\hline
\end{tabular}

(b) Continued.

\begin{tabular}{lcc}
\hline Name & $p$ value & \# molecules \\
\hline $\begin{array}{l}\text { Skeletal and muscular } \\
\text { system development and }\end{array}$ & $1.00 E-09-1.02 E-03$ & 123 \\
function & & \\
Tissue development & $1.00 E-09-1.43 E-03$ & 236 \\
\hline
\end{tabular}

(c)

\begin{tabular}{|c|c|c|}
\hline Functions annotation & $p$ value & \# molecules \\
\hline \multicolumn{3}{|c|}{$\begin{array}{l}\text { Skeletal and muscular system development and } \\
\text { function upregulated in CL1 cells }\end{array}$} \\
\hline Size of bone & $1.43 E-06$ & 24 \\
\hline $\begin{array}{l}\text { Differentiation of } \\
\text { osteoblasts }\end{array}$ & $3.84 E-06$ & 25 \\
\hline $\begin{array}{l}\text { Mineralization of } \\
\text { bone }\end{array}$ & $4.93 E-06$ & 19 \\
\hline Bone mineral density & $3.65 E-05$ & 19 \\
\hline \multicolumn{3}{|c|}{$\begin{array}{l}\text { Skeletal and muscular system development and } \\
\text { function upregulated in CL2 cells }\end{array}$} \\
\hline $\begin{array}{l}\text { Development of } \\
\text { muscle }\end{array}$ & $1.00 E-09$ & 44 \\
\hline $\begin{array}{l}\text { Proliferation of } \\
\text { muscle cells }\end{array}$ & $2.29 E-06$ & 35 \\
\hline Remodeling of bone & $3.63 E-06$ & 21 \\
\hline Resorption of bone & $3.94 E-06$ & 19 \\
\hline
\end{tabular}

confirming impairment of adipocytic differentiation of ALP deficient CL1 cells.

\section{Discussion}

We extensively studied two cell populations within cultured hBMSC that were identified based on differences in morphology. Cellular and molecular studies revealed differences in growth, differentiation capacity, and molecular signature. Our data support the notion of the presence of cellular and functional heterogeneity among cultured hBMSC.

Cellular heterogeneity of cultured hBMSC is recognized in an increasing number of reports. Several extrinsic and intrinsic factors may contribute to the observed hBMSC heterogeneity. Extrinsic factors include donor-to-donor variations in the number and quantity of initiating cells, which result in differences in cell growth rate and differentiation capacity $[14,15]$. Intrinsic factors have been examined employing single cell clonal analysis and revealed variations in differentiation potential among individual colonies within hBMSC cultures ranging from the presence of cells with trilineage (osteoblast, adipocytes, and chondrocyte) potency to cells with null potency [16]. Also, variations in the ability of clonal cells to form heterotopic bone when implanted in vivo have been reported [5]. Our study corroborates these findings and provides more detailed cellular and molecular phenotyping of two examples of cell populations that exist within the heterogeneous hBMSC cultures [17].

Determining the molecular signature of CL1 and CL2 using whole genome microarray analysis showed enrichment of lineage-commitment associated genes in CL1. For example, insulin-like growth factor 5 (IGFBP5) and interleukin 6 (IL6) 

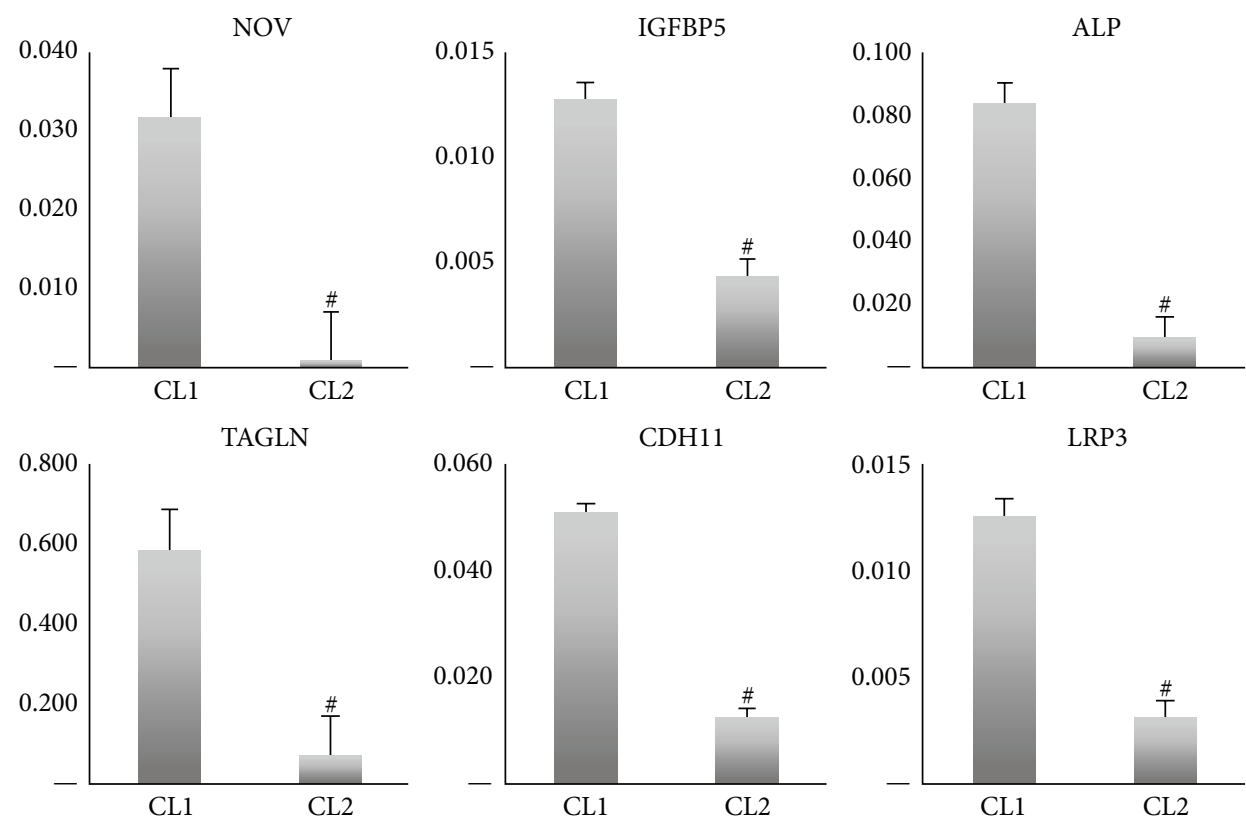

FIGURE 3: Validation of whole genome microarray analysis of two clonal populations of human bone marrow stromal stem cells: CL1 and CL2 cells. Quantitative real-time PCR for highly expressed genes in CL1 cells. NOV = nephroblastoma overexpressed, IGFBP5 = insulin-like growth factor binding protein 5, ALP, TAGLN = transgelin, and CDH11 = OB-cadherin (osteoblast). Data are presented as fold change in expression of each target gene normalized to GAPDH $\left(n=\right.$ three independent experiments, $\left.{ }^{*} p<0.001\right)$ (see also Table 3$)$.

were 14.7- and 3.3-fold upregulated in CL1 cells, respectively. Both factors are expressed in osteoprogenitor cells and important for osteoblast maturation [18]. We also observed that periostin (POSTN) gene was highly upregulated in CL1 cells (15.6-fold); POSTN is a $90 \mathrm{kDa}$ secreted protein, originally identified in murine osteoblast-like cells and is upregulated by PTH [19]. Several studies employing murine and human cells have revealed important role of POSTN in osteoblast differentiation and during development in intramembranous ossification [20-23]. Another factor identified in CL1 cells is nephroblastoma overexpression (NOV) which is a member of the Cyr 61, connective tissue growth factor $(\mathrm{CNN})$ family. The CCN family of proteins promotes osteoblast differentiation through interaction with integrins, WNT, BMP, and NOTCH signaling pathways [24-26]. In addition, a large number of signaling molecules known to be regulators of hBMSC lineage specific differentiation, for example, insulin-like growth factors [27-29], WNT [30-32], and MAPK [33-35], were enriched in CL1 cells. In contrast, CL2 expressed high levels of immune-related genes which may explain the poor differentiation response to osteoblast or adipocyte lineage. In a recent study the authors used telomerized hBMSC and showed clearly a clonal population that had very low in vitro and in vivo differentiation ability; however they had enhanced immune-related features including high IL7 expression. These nullipotent cells expressed CD317 which was associated with remarkably high basal level expression of factors with a proinflammatory and antiviral function [17]. We observed that this molecular phenotype was associated with distinct ultrastructural characteristics of the cells. In particular, CL2 had abundant phagocytic vacuole, microvilli, and lysosomes, features reminiscent of ultrastructure of immune-regulatory cells. Our data thus support the increasingly recognized feature that hBMSC exhibit immune modulatory functions and a part of the innate immune response [17].

We observed that ALP protein expression and enzymatic activity were significantly different between CL1 and CL2 cell lines and were thus a potential marker that distinguishes different cell populations with progenitor functions (CL1) from cells with nonprogenitor functions (CL2). ALP is expressed in a wide variety of tissues, including kidneys, bone, and liver [36, 37], but tissue-nonspecific ALP (ALPL) is considered a commitment marker for osteoblastic lineage $[13,38]$. However, in a recent study the authors examined the differentiation potential of a number of hMSC clones in vitro and in vivo and reported that the hMSC clones with high levels of ALP expression were committed to trilineage differentiation [13]. Our data corroborate and extend these findings by reporting the effects of siRNA-mediated inhibition of ALP that resulted in an impaired hBMSC differentiation not only to osteoblasts, but also to adipocytes. Also, our results corroborate earlier studies that demonstrated in human bone biopsies the presence of ALP expression in bone marrow adipocytic cells $[13,17]$. All these data suggest that ALP is a "stemness" marker of hBMSC and not just an indicator of osteoblastic lineage commitment.

While CL1 and CL2 were isolated from telomerized hMSC cell line, they are relevant to normal human physiology. We observed that the molecular phenotypes of CL1 and CL2 were contained within the molecular signature of primary hBMSC suggesting that CL1 and CL2 represent cell populations within the heterogeneous cultures of hBMSC. We have also previously reported that the molecular 


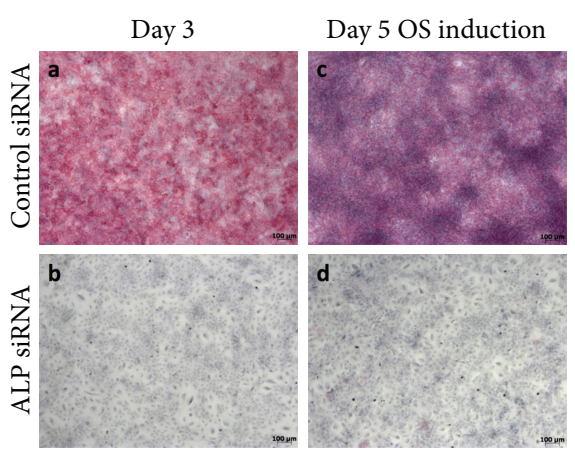

(A)

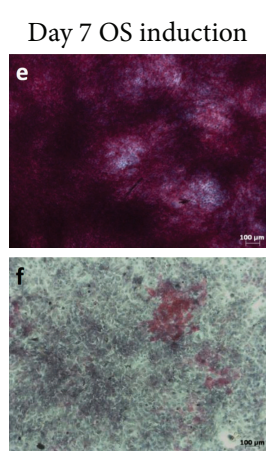

ALP siRNA

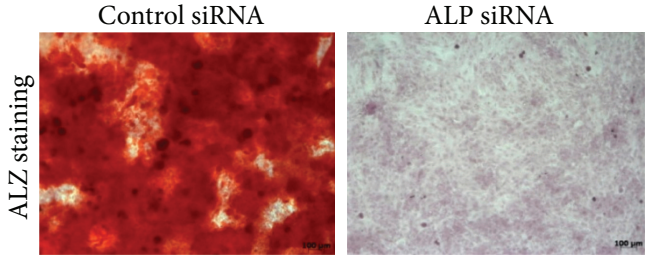

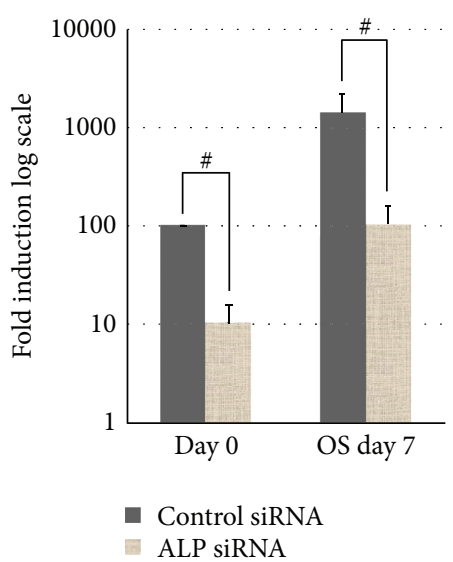

(B)

(C)
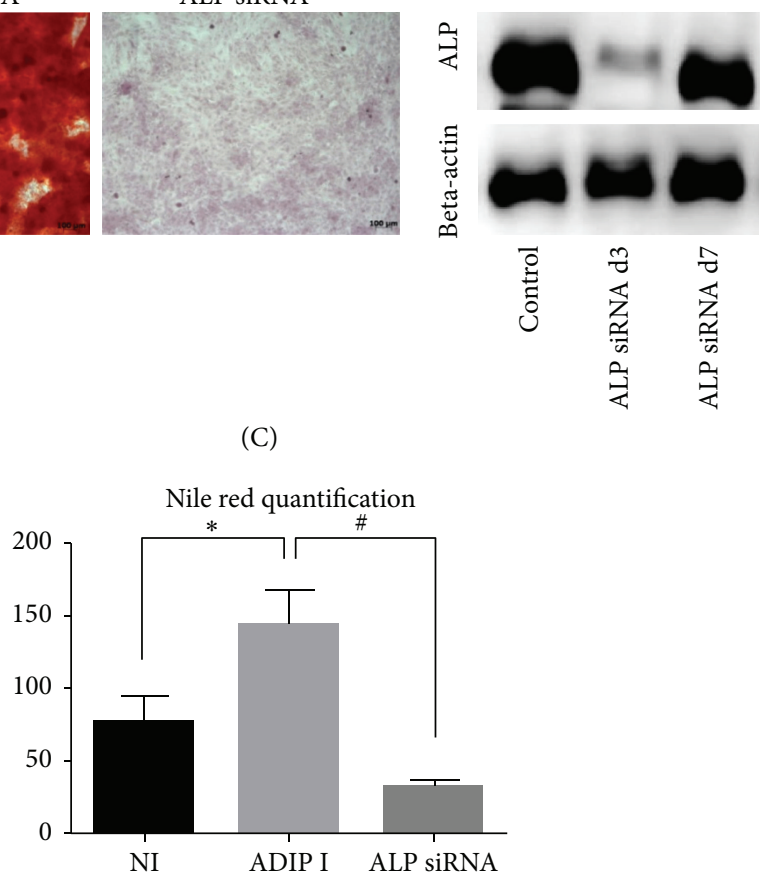

(D)

FIGURE 4: Effect of alkaline phosphatase (ALP) gene silencing by small interfering RNA (siRNA) on a clonal population of human bone marrow stromal stem cell CL1. (A) ALP staining at day 3, day 5, or day 7 days of osteoblast differentiation (OB induction). (B) Quantitative real-time PCR for ALP gene following ALP siRNA transfection at day 0 OB and day 7 of OB. Data are presented as fold change in expression of each target gene normalized to GAPDH ( $n=$ three independent experiments, ${ }^{*} p<0.01$ ). Western blotting analysis of day 3 and day 7 after siRNA ALP transfection of CL1 cells, ALPL specific antibody, and B-actin was used. (C) Mineralized matrix formation as visualized by Alizarin Red S staining in siRNA transfected CL1 cells after 14 days of OB induction. (D) Nile red quantification of mature lipid filled adipocyte in control noninduced (Cont), adipocyte induced (Adip I), and ALP siRNA transfected cells that are adipocyte induced (ALP siRNA). Adipocyte induction was carried out for 7 days. ${ }^{*} p<0.05$.

phenotype and cellular responses of hMSC-TERT are similar to those of primary hMSC [10]. While we have identified ALP as a marker that can be used for a prospective identification of differentiation committed population of hBMSC, we identified additional distinctive molecular markers of the cells. For example, IGF-1, IGF-2, and IGF binding protein 5 were enriched in CL1 compared to CL2. IGFs and their binding proteins are very well-studied factors that play a role in hBMSC proliferation and osteoblast differentiation [18]. On the other hand, annexin A3 as well as several immune-related genes was highly enriched in CL2 compared to CL1. Future studies are needed to determine the functional significance of these molecules in relation to the functional identity of various cell populations within the hBMSC cultures and their usefulness as biomarkers to dissect the heterogeneous population of cultured hBMSC.

Our finding of the presence of functional diversity within hBMSC cultures that contain progenitor and nonprogenitor 
TABLE 4: Microarray data analysis showing genes found to be upregulated during adipogenic differentiation and downregulated after ALP KO.

\begin{tabular}{|c|c|c|}
\hline $\begin{array}{l}62 \text { common elements in } \\
\text { "AD up" and "ALP down" }\end{array}$ & Gene name & $\begin{array}{l}\text { FC (ALP siRNA versus } \\
\text { control siRNA) }\end{array}$ \\
\hline APOBEC3G & Apolipoprotein B mRNA editing enzyme, catalytic polypeptide-like $3 \mathrm{G}$ & -15.938025 \\
\hline IFI44L & Interferon-induced protein 44 -like & -11.520283 \\
\hline PAQR5 & Progestin and adipoQ receptor family member V & -6.868241 \\
\hline PNMA2 & Paraneoplastic antigen MA2 & -5.9695344 \\
\hline DUSP23 & Dual specificity phosphatase 23 & -5.4786854 \\
\hline CLDN23 & Claudin 23 & -5.1885047 \\
\hline ANKDD1A & Ankyrin repeat and death domain containing $1 \mathrm{~A}$ & -5.1646647 \\
\hline IL8 & Interleukin 8 & -4.887188 \\
\hline LRRC23 & Leucine rich repeat containing 23 & -4.7611775 \\
\hline IL6 & Interleukin 6 (interferon, beta 2) & -4.693139 \\
\hline LIFR & Leukemia inhibitory factor receptor alpha & -4.6540866 \\
\hline PTGFR & Prostaglandin F receptor $(\mathrm{FP})$ & -4.457529 \\
\hline FAM134B & Family with sequence similarity 134 , member B & -4.403495 \\
\hline CYFIP2 & Cytoplasmic FMR1 interacting protein 2 & -4.260462 \\
\hline METTL7A & Methyltransferase-like 7A & -4.0480843 \\
\hline APOBEC3F & Apolipoprotein B mRNA editing enzyme, catalytic polypeptide-like $3 \mathrm{~F}$ & -3.9502614 \\
\hline CA5B & Carbonic anhydrase VB, mitochondrial & -3.93889 \\
\hline ITGA10 & Integrin, alpha 10 & -3.9143775 \\
\hline FMO3 & Flavin containing monooxygenase 3 & -3.852087 \\
\hline IMPA2 & Inositol monophosphatase 2 (human) & -3.8374884 \\
\hline $\mathrm{CDO} 1$ & Cysteine dioxygenase, type I & -3.8181455 \\
\hline CCDC68 & Coiled-coil domain containing 68 & -3.7292893 \\
\hline CXCL1 & $\begin{array}{l}\text { Chemokine (C-X-C motif) ligand } 1 \text { (melanoma growth stimulating activity, } \\
\text { alpha) }\end{array}$ & -3.5942702 \\
\hline IDO1 & Indoleamine 2,3-dioxygenase 1 & -3.5803545 \\
\hline KCNIP3 & Kv channel interacting protein 3 , calsenilin & -3.5442894 \\
\hline FADS1 & Fatty acid desaturase 1 & -3.2951858 \\
\hline LSR & Lipolysis stimulated lipoprotein receptor & -3.2215986 \\
\hline ITGA7 & Integrin, alpha 7 & -3.1355932 \\
\hline HLA-DMA & Major histocompatibility complex, class II, DM alpha & -3.1347752 \\
\hline AРОВЕС3В & Apolipoprotein B mRNA editing enzyme, catalytic polypeptide-like 3B & -3.1074922 \\
\hline BMP4 & Bone morphogenetic protein 4 & -3.0809238 \\
\hline DMBT1 & Deleted in malignant brain tumors 1 & -3.0760298 \\
\hline RDH5 & Retinol dehydrogenase 5 (11-cis/9-cis) & -3.066812 \\
\hline EPAS1 & Endothelial PAS domain protein 1 & -3.0615559 \\
\hline CDKN3 & Cyclin-dependent kinase inhibitor 3 & -3.052319 \\
\hline GPC6 & Glypican 6 & -3.0460389 \\
\hline CDK4 & Cyclin-dependent kinase 4 & -2.9808035 \\
\hline FKBP5 & FK506 binding protein 5 & -2.9360793 \\
\hline PDE1B & Phosphodiesterase 1B, calmodulin-dependent & -2.8863106 \\
\hline JAM2 & Junctional adhesion molecule 2 & -2.884354 \\
\hline TFPI & Tissue factor pathway inhibitor (lipoprotein-associated coagulation inhibitor) & -2.8578906 \\
\hline NT5M & $5^{\prime}, 3^{\prime}$-Nucleotidase, mitochondrial & -2.7555947 \\
\hline NFIA & Nuclear factor I/A & -2.7176137 \\
\hline TSPAN31 & Tetraspanin 31 & -2.627556 \\
\hline ZNF25 & Zinc finger protein 25 & -2.6183622 \\
\hline SULF2 & Sulfatase 2 & -2.5464642 \\
\hline MESP1 & Mesoderm posterior 1 homolog (mouse) & -2.525513 \\
\hline
\end{tabular}


TABLE 4: Continued.

\begin{tabular}{|c|c|c|}
\hline $\begin{array}{l}62 \text { common elements in } \\
\text { "AD up" and "ALP down" }\end{array}$ & Gene name & $\begin{array}{l}\text { FC (ALP siRNA versus } \\
\text { control siRNA) }\end{array}$ \\
\hline BCL2L1 & BCL2-like 1 & -2.5119667 \\
\hline PLTP & Phospholipid transfer protein & -2.4767148 \\
\hline TIMP4 & TIMP metallopeptidase inhibitor 4 & -2.465897 \\
\hline CYP27A1 & Cytochrome P450, family 27, subfamily A, polypeptide 1 & -2.4572072 \\
\hline TTC39B & Tetratricopeptide repeat domain $39 \mathrm{~B}$ & -2.4439611 \\
\hline IL1R2 & Interleukin 1 receptor, type II & -2.427431 \\
\hline FMOD & Fibromodulin & -2.4185398 \\
\hline LDLRAD3 & Low density lipoprotein receptor class A domain containing 3 & -2.4032724 \\
\hline PISD & Phosphatidylserine decarboxylase & -2.3884957 \\
\hline TMEM100 & Transmembrane protein 100 & -2.384632 \\
\hline CHST2 & Carbohydrate ( $\mathrm{N}$-acetylglucosamine-6-O) sulfotransferase 2 & -2.3805838 \\
\hline APOBEC3F & Apolipoprotein B mRNA editing enzyme, catalytic polypeptide-like $3 \mathrm{~F}$ & -2.3759322 \\
\hline SCD & Stearoyl-CoA desaturase (delta-9-desaturase) & -2.3524246 \\
\hline SPAG4 & Sperm associated antigen 4 & -2.280867 \\
\hline MMD & Monocyte to macrophage differentiation associated human & -2.2055967 \\
\hline ASS1 & Argininosuccinate synthase 1 & -2.1725202 \\
\hline GK5 & Glycerol kinase 5 (putative) & -2.1667244 \\
\hline PDE7B & Phosphodiesterase 7B & -2.166515 \\
\hline MT1X & Metallothionein $1 \mathrm{X}$ & -2.161843 \\
\hline $\mathrm{ACACB}$ & Acetyl-CoA carboxylase beta & -2.1512873 \\
\hline LEPR & Leptin receptor & -2.148686 \\
\hline HIF1A & $\begin{array}{l}\text { Hypoxia inducible factor 1, alpha subunit (basic helix-loop-helix transcription } \\
\text { factor) }\end{array}$ & -2.0954225 \\
\hline HEXDC & Hexosaminidase (glycosyl hydrolase family 20, catalytic domain) containing & -2.094836 \\
\hline SARM1 & Sterile alpha and TIR motif containing 1 & -2.0797038 \\
\hline BBS1 & Bardet-Biedl syndrome 1 & -2.0146718 \\
\hline SERPING1 & Serpin peptidase inhibitor, clade $\mathrm{G}$ ( $\mathrm{C} 1$ inhibitor), member 1 & -2.0102212 \\
\hline FAM162A & Family with sequence similarity 162, member A & -2.005807 \\
\hline TCTN1 & Tectonic family member 1 & -2.0033443 \\
\hline
\end{tabular}

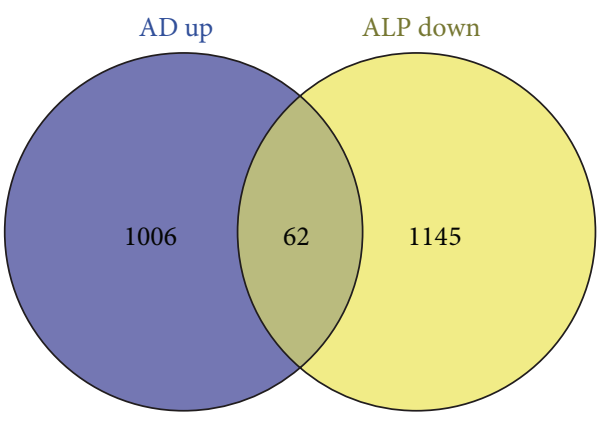

(a)

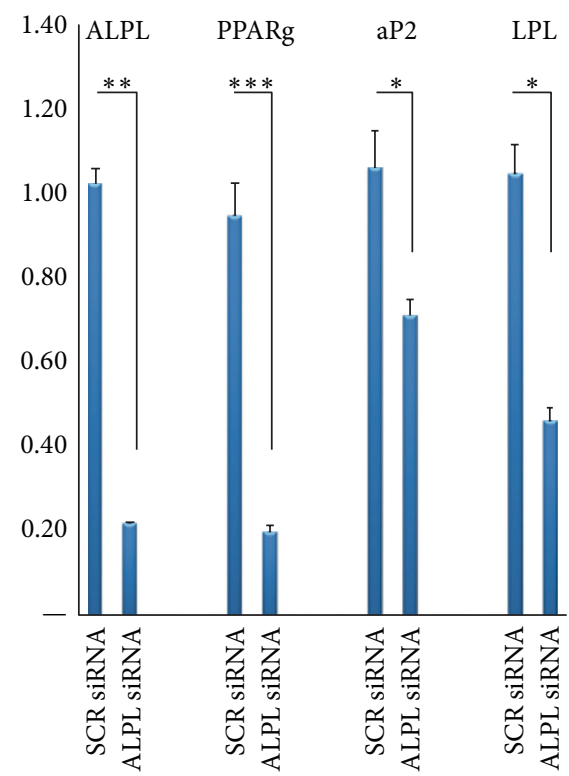

(b)

FIGURE 5: Adipocyte related genes downregulated in ALP knockdown CL1 cells. (a) Venn diagram of whole gene expression analysis of AD upregulated genes compared with ALP KD downregulated genes. (b) Quantitative real-time PCR of four selected common genes from Venn diagram including ALPL, PPARg2, aP2, and LPL. Data are presented as fold change in expression of each target gene normalized to GAPDH ( $n=$ three independent experiments, ${ }^{*} p<0.05,{ }^{* *} p<0.01$, and ${ }^{* * *} p<0.001$ ). 
cell populations has a clinical relevance. It demonstrates that the progenitor function and the immune modulatory roles of hBMSC [39] are mediated by specific and distinguishable populations of hBMSC. Thus, future clinical studies employing hBMSC should attempt to administer the relevant subpopulation of hBMSC dependent on the experimental aim, as a novel approach to improving the clinical efficiency, instead of the current use of heterogeneous hBMSC populations.

\section{Competing Interests}

The authors declare that they have no competing interests.

\section{Authors' Contributions}

Mona Elsafadi and Amer Mahmood contributed equally to this work.

\section{Acknowledgments}

These studies are supported by a grant from the College of Medicine Research Centre (CMRC), Deanship of Scientific Research, King Saud University, Riyadh, Saudi Arabia. The authors would like to thank Mr. Ali Al-Roalle for all his technical help. They thank Natalie Twine for advice on DNA microarray analysis.

\section{References}

[1] W. Zaher, L. Harkness, A. Jafari, and M. Kassem, "An update of human mesenchymal stem cell biology and their clinical uses," Archives of Toxicology, vol. 88, no. 5, pp. 1069-1082, 2014.

[2] S. Post, B. M. Abdallah, J. F. Bentzon, and M. Kassem, "Demonstration of the presence of independent pre-osteoblastic and pre-adipocytic cell populations in bone marrow-derived mesenchymal stem cells," Bone, vol. 43, no. 1, pp. 32-39, 2008.

[3] K. H. Larsen, C. M. Frederiksen, J. S. Burns, B. M. Abdallah, and M. Kassem, "Identifying a molecular phenotype for bone marrow stromal cells with in vivo bone-forming capacity," Journal of Bone and Mineral Research, vol. 25, no. 4, pp. 796$808,2010$.

[4] A. Rosenzweig, "Cardiac cell therapy-mixed results from mixed cells," The New England Journal of Medicine, vol. 355, no. 12, pp. 1274-1277, 2006.

[5] S. A. Kuznetsov, P. H. Krebsbach, K. Satomura et al., "Singlecolony derived strains of human marrow stromal fibroblasts form bone after transplantation in vivo," Journal of Bone and Mineral Research, vol. 12, no. 9, pp. 1335-1347, 1997.

[6] M. Kassem and P. Bianco, "Skeletal stem cells in space and time," Cell, vol. 160, no. 1-2, pp. 17-19, 2015.

[7] A. I. Caplan and D. Correa, "PDGF in bone formation and regeneration: new insights into a novel mechanism involving MSCs," Journal of Orthopaedic Research, vol. 29, no. 12, pp. 17951803, 2011.

[8] K. Stewart, S. Walsh, J. Screen et al., "Further characterization of cells expressing STRO-1 in cultures of adult human bone marrow stromal cells," Journal of Bone and Mineral Research, vol. 14, no. 8, pp. 1345-1356, 1999.

[9] J. L. Simonsen, C. Rosada, N. Serakinci et al., "Telomerase expression extends the proliferative life-span and maintains the osteogenic potential of human bone marrow stromal cells," Nature Biotechnology, vol. 20, no. 6, pp. 592-596, 2002.

[10] M. Al-Nbaheen, R. Vishnubalaji, D. Ali et al., "Human stromal (mesenchymal) stem cells from bone marrow, adipose tissue and skin exhibit differences in molecular phenotype and differentiation potential," Stem Cell Reviews and Reports, vol. 9, no. 1, pp. 32-43, 2013.

[11] C. A. Gregory, W. G. Gunn, A. Peister, and D. J. Prockop, "An Alizarin red-based assay of mineralization by adherent cells in culture: comparison with cetylpyridinium chloride extraction," Analytical Biochemistry, vol. 329, no. 1, pp. 77-84, 2004.

[12] A. Mahmood, L. Harkness, H. D. Schrøder, B. M. Abdallah, and M. Kassem, "Enhanced differentiation of human embryonic stem cells to mesenchymal progenitors by inhibition of TGF$\beta /$ activin/nodal signaling using SB-431542," Journal of Bone and Mineral Research, vol. 25, no. 6, pp. 1216-1233, 2010.

[13] H.-J. Prins, A. K. Braat, D. Gawlitta et al., "In vitro induction of alkaline phosphatase levels predicts in vivo bone forming capacity of human bone marrow stromal cells," Stem Cell Research, vol. 12, no. 2, pp. 428-440, 2014.

[14] K. Stenderup, J. Justesen, C. Clausen, and M. Kassem, "Aging is associated with decreased maximal life span and accelerated senescence of bone marrow stromal cells," Bone, vol. 33, no. 6, pp. 919-926, 2003.

[15] D. G. Phinney, G. Kopen, W. Righter, S. Webster, N. Tremain, and D. J. Prockop, "Donor variation in the growth properties and osteogenic potential of human marrow stromal cells," Journal of Cellular Biochemistry, vol. 75, no. 3, pp. 424-436, 1999.

[16] C. M. Digirolamo, D. Stokes, D. Colter, D. G. Phinney, R. Class, and D. J. Prockop, "Propagation and senescence of human marrow stromal cells in culture: a simple colony-forming assay identifies samples with the greatest potential to propagate and differentiate," British Journal of Haematology, vol. 107, no. 2, pp. 275-281, 1999.

[17] S. James, J. Fox, F. Afsari et al., "Multiparameter analysis of human bone marrow stromal cells identifies distinct immunomodulatory and differentiation-competent subtypes," Stem Cell Reports, vol. 4, no. 6, pp. 1004-1015, 2015.

[18] B. Peruzzi, A. Cappariello, A. Del Fattore, N. Rucci, F. De Benedetti, and A. Teti, "c-Src and IL-6 inhibit osteoblast differentiation and integrate IGFBP5 signalling," Nature Communications, vol. 3, article 630, 2012.

[19] D. Fortunati, S. Reppe, Å.-K. Fjeldheim, M. Nielsen, V. T. Gautvik, and K. M. Gautvik, "Periostin is a collagen associated bone matrix protein regulated by parathyroid hormone," Matrix Biology, vol. 29, no. 7, pp. 594-601, 2010.

[20] A. Oshima, H. Tanabe, T. Yan, G. N. Lowe, C. A. Glackin, and A. Kudo, "A novel mechanism for the regulation of osteoblast differentiation: transcription of periostin, a member of the fasciclin I family, is regulated by the bHLH transcription factor, Twist," Journal of Cellular Biochemistry, vol. 86, no. 4, pp. 792804, 2002.

[21] T. G. Kashima, T. Nishiyama, K. Shimazu et al., "Periostin, a novel marker of intramembranous ossification, is expressed in fibrous dysplasia and in c-Fos-overexpressing bone lesions," Human Pathology, vol. 40, no. 2, pp. 226-237, 2009.

[22] C. Galli, M. Piergianni, M. Piemontese et al., "Periostin improves cell adhesion to implantable biomaterials and osteoblastic differentiation on implant titanium surfaces in a topographydependent fashion," Journal of Biomedical Materials Research Part A, vol. 102, no. 11, pp. 3855-3861, 2014. 
[23] D. L. Coutu, H. W. Jian, A. Monette, G.-É. Rivard, M. D. Blostein, and J. Galipeau, "Periostin, a member of a novel family of vitamin K-dependent proteins, is expressed by mesenchymal stromal cells," The Journal of Biological Chemistry, vol. 283, no. 26, pp. 17991-18001, 2008.

[24] T. Minamizato, K. Sakamoto, T. Liu et al., "CCN3/NOV inhibits BMP-2-induced osteoblast differentiation by interacting with BMP and Notch signaling pathways," Biochemical and Biophysical Research Communications, vol. 354, no. 2, pp. 567-573, 2007.

[25] W. Si, Q. Kang, H. H. Luu et al., "CCN1/Cyr61 is regulated by the canonical Wnt signal and plays an important role in Wnt3Ainduced osteoblast differentiation of mesenchymal stem cells," Molecular and Cellular Biology, vol. 26, no. 8, pp. 2955-2964, 2006.

[26] Q. Luo, Q. Kang, W. Si et al., "Connective tissue growth factor (CTGF) is regulated by Wnt and bone morphogenetic proteins signaling in osteoblast differentiation of mesenchymal stem cells," The Journal of Biological Chemistry, vol. 279, no. 53, pp. 55958-55968, 2004.

[27] Y.-S. Yoon, N. Lee, and H. Scadova, "Myocardial regeneration with bone-marrow-derived stem cells," Biology of the Cell, vol. 97, no. 4, pp. 253-263, 2005.

[28] Y. S. Yoon, "Cardiac regeneration with novel bone marrowderived multipotent stem cells," Discovery Medicine, vol. 5, pp. 204-208, 2005.

[29] Y.-S. Yoon, A. Wecker, L. Heyd et al., "Clonally expanded novel multipotent stem cells from human bone marrow regenerate myocardium after myocardial infarction," Journal of Clinical Investigation, vol. 115, no. 2, pp. 326-338, 2005.

[30] G. M. Boland, G. Perkins, D. J. Hall, and R. S. Tuan, "Wnt 3a promotes proliferation and suppresses osteogenic differentiation of adult human mesenchymal stem cells," Journal of Cellular Biochemistry, vol. 93, no. 6, pp. 1210-1230, 2004.

[31] D. A. Cook, S. W. Fellgett, M. E. Pownall, P. J. O’Shea, and P. G. Genever, "Wnt-dependent osteogenic commitment of bone marrow stromal cells using a novel GSK $3 \beta$ inhibitor," Stem Cell Research, vol. 12, no. 2, pp. 415-427, 2014.

[32] J. De Boer, R. Siddappa, C. Gaspar, A. Van Apeldoorn, R. Fodde, and C. Van Blitterswijk, "Wnt signaling inhibits osteogenic differentiation of human mesenchymal stem cells," Bone, vol. 34, no. 5, pp. 818-826, 2004.

[33] M. Al-Toub, A. Almusa, M. Almajed et al., "Pleiotropic effects of cancer cells' secreted factors on human stromal (mesenchymal) stem cells," Stem Cell Research and Therapy, vol. 4, article 114, 2013.

[34] L. Chen, D. Qanie, A. Jafari et al., "Delta-like 1/fetal antigen-1 (Dlk1/FA1) is a novel regulator of chondrogenic cell differentiation via inhibition of the Akt kinase-dependent pathway," The Journal of Biological Chemistry, vol. 286, no. 37, pp.32140-32149, 2011.

[35] T. Matsunobu, K. Torigoe, M. Ishikawa et al., "Critical roles of the TGF- $\beta$ type I receptor ALK5 in perichondrial formation and function, cartilage integrity, and osteoblast differentiation during growth plate development," Developmental Biology, vol. 332, no. 2, pp. 325-338, 2009.

[36] B. C. Nair, D. E. Johnson, R. J. Majeska, J. A. Rodkey, C. D. Bennett, and G. A. Rodan, "Rat alkaline phosphatase. II. Structural similarities between the osteosarcoma, bone, kidney, and placenta isoenzymes," Archives of Biochemistry and Biophysics, vol. 254, no. 1, pp. 28-34, 1987.
[37] P. J. Butterworth, "Alkaline phosphatase. Biochemistry of mammalian alkaline phosphatases," Cell Biochemistry and Function, vol. 1, no. 2, pp. 66-70, 1983.

[38] A. T. Ali, C. B. Penny, J. E. Paiker et al., "Alkaline phosphatase is involved in the control of adipogenesis in the murine preadipocyte cell line, 3T3-L1," Clinica Chimica Acta, vol. 354, no. 1-2, pp. 101-109, 2005.

[39] G. M. Spaggiari and L. Moretta, "Cellular and molecular interactions of mesenchymal stem cells in innate immunity," Immunology and Cell Biology, vol. 91, no. 1, pp. 27-31, 2012. 

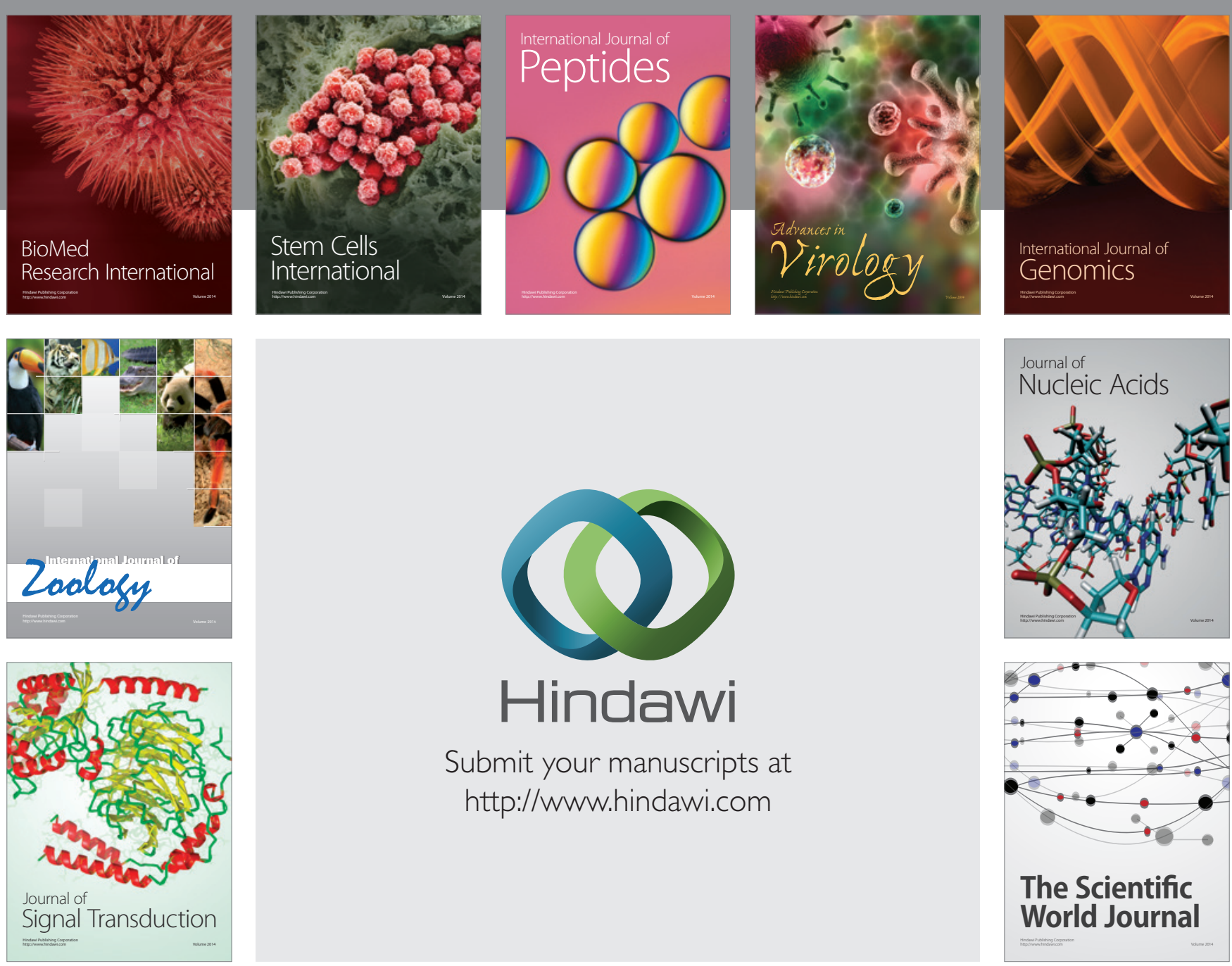

Submit your manuscripts at

http://www.hindawi.com
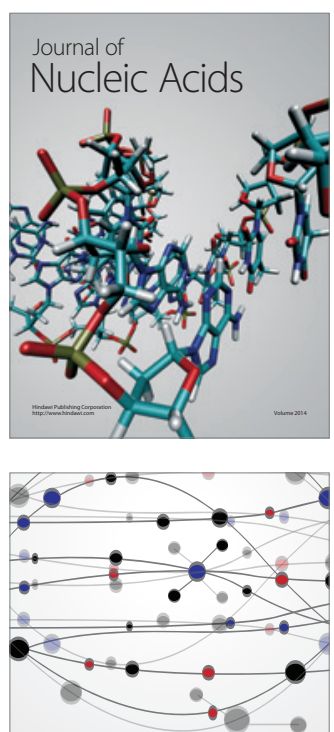

The Scientific World Journal
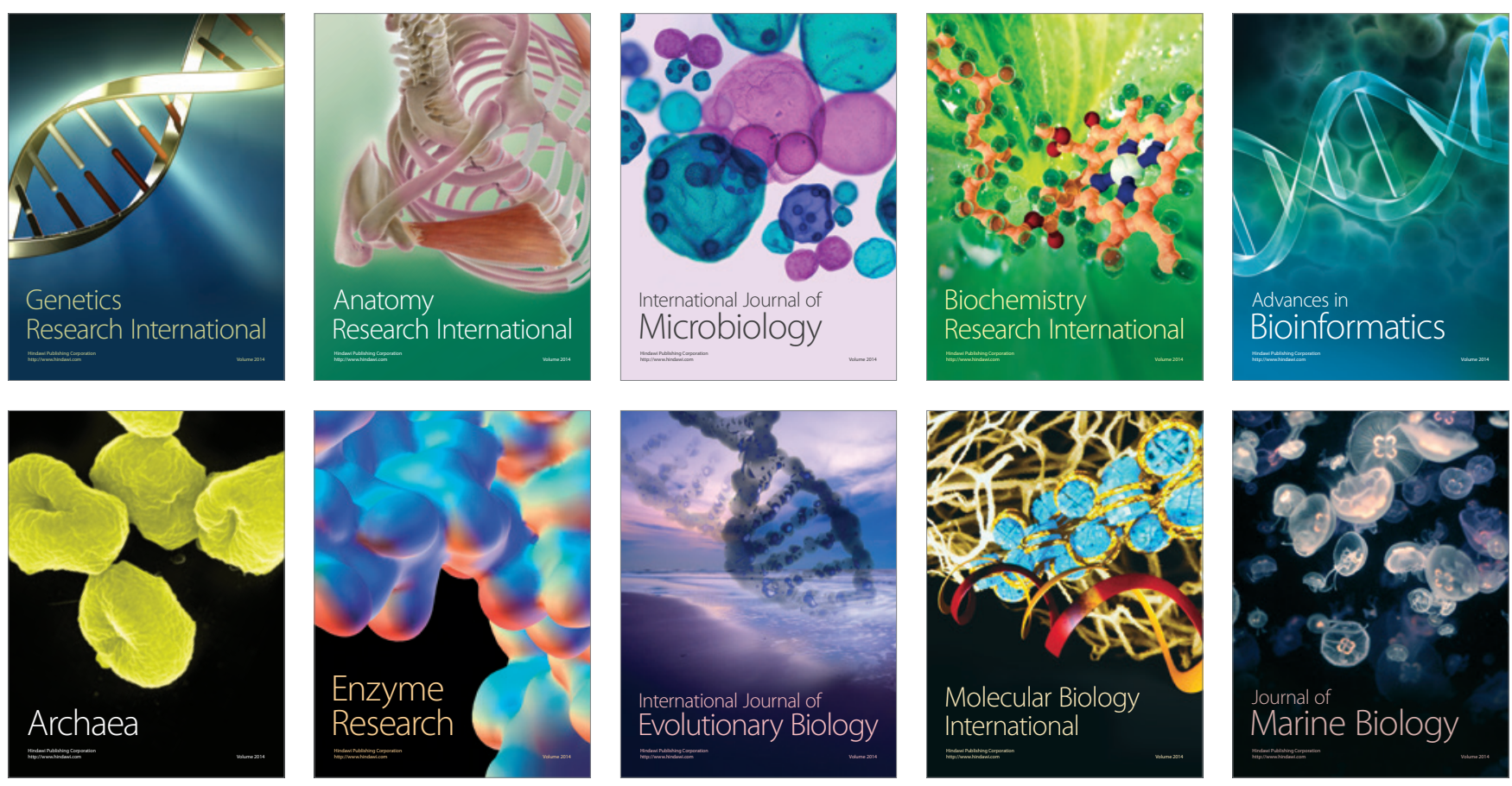